\title{
Up-Regulation of Matrix Metalloproteinase-2 by Scleral Monocyte-Derived Macrophages Contributes to Myopia Development
}

Fei Zhao, ${ }^{*^{\dagger}}$ Hao Wu, ${ }^{{ }^{\dagger}}$ Peter S. Reinach, ${ }^{{ }^{\dagger}}$ Yi Wu,${ }^{* \dagger}$ Ying Zhai, ${ }^{*^{\dagger}}$ Yi Lei, ${ }^{* \dagger}$ Li Ma, ${ }^{{ }^{\dagger}}$ Yongchao Su, ${ }^{*^{\dagger}}$ Yizhong Chen, ${ }^{{ }^{\dagger}}$ Fen $\mathrm{Li},{ }^{+\dagger}$ Xing Liu, ${ }^{{ }^{\dagger}}$ Nethrajeith Srinivasalu, ${ }^{* \dagger}$ Jia Qu, ${ }^{* \dagger}$ and Xiangtian Zhou ${ }^{* \dagger}$

From the School of Optometry and Ophthalmology and Eye Hospital, * Wenzhou Medical University, Wenzhou; and the The State Key Laboratory of Optometry, Ophthalmology and Vision Science, ${ }^{\dagger}$ Wenzhou, China

Accepted for publication

June 1, 2020.

Address correspondence to Xiangtian Zhou, M.D., Ph.D., School of Optometry and Ophthalmology and Eye Hospital, Wenzhou Medical University, 270 W. Xueyuan Rd., Wenzhou, Zhejiang, China. Email: zxt@mail.eye.ac.cn.

\begin{abstract}
Myopia is a leading cause of visual impairment worldwide. This sight-compromising condition is associated with scleral thinning, extracellular matrix remodeling, and inappropriate optical axial length elongation. Although macrophages are present in the sclera, their involvement in this condition is unknown. By using a form-deprivation myopia (FDM) mouse model, we found that both the scleral macrophage density and their matrix metalloproteinase-2 (MMP-2) expression levels increased in myopic eyes. Partial scleral macrophage depletion by clodronate shifted the refraction toward hyperopia in both the form-deprived and the untreated fellow eyes compared with their respective counterparts in the vehicle-injected control mice. However, this procedure did not alter susceptibility to FDM. FDM development was $59 \%$ less in the macrophage-specific Mmp2 deletion (LysM ${ }^{\mathrm{Cre}} \mathrm{Mmp}-2^{\mathrm{fl} / \mathrm{fl}}$ ) mice than in their Cre-negative littermates $\left(M m p 2^{f l / f l}\right.$ mice). Moreover, the expression of scleral C-C motif chemokine ligand-2 (CCL2), which is a potent monocyte chemoattractant recruiting monocytes to tissue sites, was increased during myopia progression. However, the increase in the density of scleral macrophages and myopia development were suppressed in fibroblast-specific $\mathrm{Ccl} 2$ deletion mice. These declines suggested that the increase in scleral macrophage density in myopic eyes stems from the up-regulation of scleral Ccl2 expression in fibroblasts, which, in turn, promotes monocytes recruitment. In summary, scleral monocyte-derived macrophages contribute to myopia development through enhancing MMP-2 expression in mice. (Am J Pathol 2020, 190: 1888-1908; https://doi.org/10.1016/j.ajpath.2020.06.002)
\end{abstract}

Worldwide, myopia is the most prevalent refractive error. ${ }^{1,2}$ In less severe cases, distance vision is blurred, whereas more severe cases can lead to a variety of sight-threatening impairments, including retinal detachment, cataract, subretinal neovascularization, glaucoma, and even blindness. ${ }^{3}$ Although orthokeratology and low concentrations of atropine may slow myopia progression in children, each of these treatments can have severe adverse effects. ${ }^{4}$ These limitations are prompting efforts to identify novel targets whose modulation can potentially improve therapeutic management of this condition in a clinical setting.

In human myopia and mammalian myopia models, excessive axial length (AL) elongation and increases in vitreous chamber depth (VCD) accompany declines in collagen biosynthesis and increases in proteolysis of the collagenous structural framework and extracellular matrix (ECM) remodeling in the sclera, particularly at the posterior region of the eye. ${ }^{5}$ Scleral matrix metalloproteinase-2 (MMP-2) up-regulation is one of the proteolytic changes contributing to ECM remodeling. ${ }^{6-11}$ It is a member of the

Supported by the National Natural Science Foundation of China grants 81170870 (X.Z.), 81700868 (F.Z.), 81422007 (X.Z.), 81670886 (X.Z.), 81830027 (J.Q.), and 81470659 (J.Q.); Natural Science Foundation of Zhejiang Province grants LZ14H120001 (X.Z.) and LQ16H120006 (F.Z.); Scientific Bureau of Wenzhou City grant Y20180510 (Y.Z.); Zhejiang Provincial Program for the Cultivation of High-Level Innovative Health Talents (X.Z.); and The National Young Excellent Talents Support Program (X.Z.).

F.Z. and H.W. contributed equally to this work.

Disclosures: None declared. 
zinc-dependent endopeptidase family, which degrades type I collagen and most of the ECM components under both physiological and pathologic conditions. Fibroblasts, which are the predominant scleral cell type, contribute to MMP-2 up-regulation and type I collagen degradation in a formdeprivation myopia (FDM) mouse model. ${ }^{6}$ Despite such increases, myopia was suppressed by only $27 \%$ in the fibroblast-specific Mmp2 deletion mice. ${ }^{6}$ One possible explanation for this relatively small inhibition is that there are other cell types besides fibroblasts contributing to scleral MMP-2 up-regulation.

This supposition was in accord with reports describing the presence of a large number of macrophages in the scleras of humans ${ }^{12,13}$ and rodents, ${ }^{14}$ especially at the posterior region. In other tissues, these immune cells play important roles in ECM remodeling and tissue homeostasis under both physiological and pathologic conditions. ${ }^{15-17}$ Therefore, macrophages may contribute to myopia progression because MMP-2 up-regulation is associated with increases in their infiltration in some other tissues. ${ }^{18,19}$

Herein, we show that scleral macrophages are another MMP-2 source because increases in their density parallel increases in MMP-2 expression during myopia progression in a well-established FDM mouse model. These increases are driven by the up-regulation of C-C motif chemokine ligand-2 ( $\mathrm{Ccl} 2)$ expression in fibroblast. This chemokine, in turn, induces infiltration of circulating monocytes into the sclera, and they subsequently differentiate into MMP-2-secreting macrophages. Taken together, scleral monocyte-derived macrophages contribute to scleral MMP-2 up-regulation during myopia progression.

\section{Materials and Methods}

Mice

All animals were bred in the animal breeding unit at Wenzhou Medical University (Wenzhou, China) and raised in standard mouse cages at $22^{\circ} \mathrm{C} \pm 2{ }^{\circ} \mathrm{C}$ with a 12 -hour light/12-hour dark cycle. The lights were turned on at 8:30 AM every day. During the light phase, the luminance was approximately 100 to 200 lux. All animal experiments were approved by the Animal Care and Ethics Committee at Wenzhou Medical University and conducted according to the Association for Research in Vision and Ophthalmology Statement for the Use of Animals in Ophthalmic and Visual Research.

\section{Generation of Macrophage-Specific tdTomato Expression}

Mice

LysM $^{\text {Cre }}$ mice $^{20} \quad[$ C57BL/6J background, B6.129P2-

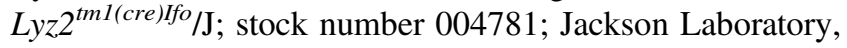
Bar Harbor, ME] were crossed with Rosa26-stop-floxtdTomato mice ${ }^{21}$ [developed on a C57BL/6J background,

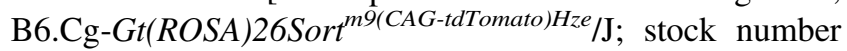
007909; Jackson Laboratory] to generate LysM ${ }^{\text {Cre }}$ Rosa26 $6^{\mathrm{f} / \mathrm{fl}}$ mice. In these mice, the STOP cassette is deleted in LysMexpressing cells (including monocytes and macrophages), resulting in red tdTomato fluorescence in these cells.

Generation of Macrophage-Specific Mmp2 Deletion Mice $\mathrm{Mmp} 2^{\mathrm{fl} / \mathrm{fl}}$ mice were developed on a C57BL/6J background at the Model Animal Research Center of Nanjing University (Nanjing, China). ${ }^{6} \mathrm{Mmp}^{f / f t}$ mice were crossed with LysM $^{\text {Cre }}$ mice to generate macrophage-specific Mmp2 deletion mice $\left(\mathrm{LysM}^{\mathrm{Cre}} \mathrm{Mmp} 2^{\mathrm{fl} / \mathrm{fl}}\right.$ ) and their Cre-negative littermates (designated $M m p 2^{f l / f}$ ).

\section{Generation of Fibroblast-Specific Ccl2 Deletion Mice} $\mathrm{Ccl} 2^{f l f l} \mathrm{mice}^{22} \quad$ [C57BL/6NJ background,

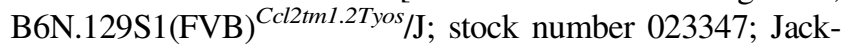
son Laboratory] were crossed with S100a4 ${ }^{\text {Cre }}$ mice $^{23}$ [BALB/ cByJ background, BALB/c-Tg(S100a4-cre) 1 Egn/YunkJ; stock number 012641; Jackson Laboratory] to generate fibroblast-specific $\mathrm{Ccl} 2$ deletion mice $\left(\mathrm{S1OOa} 4^{\mathrm{Cre}} \mathrm{Ccl}{ }^{\mathrm{flfl}}\right)$ and their $\mathrm{Cre}$-negative littermates (designated $\mathrm{Ccl} 2^{f / f l}$ ).

PCR analysis of tail-extracted genomic DNA using specific primers (Table 1) confirmed all mouse genotype identities.

\section{Induction of FDM and Ocular Biometric Measurements}

Monocular FDM was induced by covering the right eye of each mouse with a handmade white translucent occluder. $^{24,25}$ It was carefully attached with polystyrene glue to the fur around the eye so as to prevent exposure to any direct unfiltered light. To prevent the mice from removing the occluder, a collar made of thin plastic was fitted around the neck. The form-deprivation (FD)-treated right eyes were designated as FD-T, and the untreated left fellow eyes were designated as FD-F. Ocular refraction without cycloplegia was measured using an eccentric infrared photorefractor in a dark room. Each measurement was repeated three times to obtain a final mean refraction. ${ }^{24}$ The ocular biometric parameters, AL (refers to the distance from the corneal apex to the nerve fiber layer of the retina), VCD (refers to the distance from the back of the lens to the nerve fiber layer of the retina), lens thickness (refers to the distance from its anterior to posterior surface), and anterior chamber depth (refers to the distance between the posterior surface of the cornea and the anterior surface of the lens), were measured using a custom-made optical coherence tomography instrument. ${ }^{24}$

\section{Animal Experiment Designs}

Supplemental Figure S1 provides a diagrammatic representation of the experimental design.

Four-week-old wild-type male C57BL/6 mice with anisometropia (the difference in refraction between right and left eyes) of $<3$ diopters (D), and free of injuries and infections, were used in this study. The mice were randomly divided into FD and age-matched control groups. In the FD 
group, the right eye (designated FD-T) of each mouse was form deprived for $1,1.25,1.5,1.75,2,2.25,2.5,7$, or 14 days, and the untreated left eye constituted the fellow eye control group (designated FD-F). Age-matched mice with no FD induction served as normal controls (designated normal). After 14 days of FD induction, scleral tissues of the mice were prepared for co-immunofluorescence labeling of MMP-2 and F4/80, a macrophage-specific antigen. ${ }^{26}$ MMP-2 is synthesized and secreted in a latent form and converted into an active form in the extracellular environment. ${ }^{27}$ However, there are no specific antibodies available to distinguish between these two forms. To assess if macrophages contribute to scleral MMP-2 up-regulation, frozen scleral sections were used to evaluate macrophage-specific $\left(\mathrm{F} 4 / 80^{+}\right)$MMP-2 expression in FD-treated mice. Quantitative real-time RT-PCR (RT-qPCR) determined the timedependent $(1,1.25,1.5,1.75,2,2.25,2.5,7$, and 14 days) differential expression levels of scleral MMP-2 and macrophage-related protein encoding genes. To determine if these scleral gene expression levels follow a circadian rhythm, their expression levels were measured at 3:00 AM, 9:00 AM, 3:00 PM, and 9:00 PM across a single day in 4week-old C57BL/6J mice. At these time points, the scleral tissues were isolated and prepared for RT-qPCR analysis.

Scleral monocyte and macrophage densities were also evaluated on the basis of immunofluorescence staining of the endogenous $L y s M$ gene promoter, which is a specific marker of these cell types. Red tdTomato fluorescence evaluated Lys $M$ promoter-driven Cre recombinase expression during FDM progression in $\mathrm{LysM}^{\mathrm{Cre}} \mathrm{Rosa} 26^{\mathrm{f} / \mathrm{fl}}$ mice. In addition, F4/80 colabeling was used to validate the correspondence between tdTomato expression and scleral macrophage presence. Four-week-old LysM $^{\text {Cre }}$ Rosa2 $6^{\mathrm{f} / \mathrm{fl}}$ mice were randomly divided into the FD and normal groups. In the FD group, the right eye of each mouse was form deprived (FD-T eyes) for 2, 7, or 14 days, whereas the left fellow eyes (FD-F eyes) were untreated. Age-matched untreated LysM $^{\mathrm{Cre}} \mathrm{R}$ osa $26^{\mathrm{f} / \mathrm{fl}}$ mice served as the normal controls (normal).

To assess the effect of macrophage-specific Mmp2 deletion on normal refractive development, the ocular measurements were performed from postnatal day (P) 28 (week 4) to P70 (week 10) in both $M m p 2^{f / / f}(n=25)$ and LysM $^{\mathrm{Cre}} \mathrm{Mmp}-2^{\mathrm{t} / \mathrm{fl}}(n=22)$ mice. To assess the effect of macrophage-specific Mmp2 deletion on FDM development, 4 weeks of FD were performed in $\operatorname{Mmp}^{f l / f l}(n=14)$ and LysM $^{\mathrm{Cre}} \mathrm{Mmp}-2^{\mathrm{ff} / \mathrm{fl}}(n=24)$ mice. The FD treatment was initiated at 4 weeks of age. Another 10 untreated animals from each genotype served as the age-matched controls. Ocular measurements were recorded before and after 4 weeks of FD. The scleral tissues obtained from these mice were prepared for RT-qPCR analysis of $M m p 2$ expression and immunofluorescence labeling of F4/80 and MMP-2.

Clodronate (CLOD) encapsulated within the liposomes (Liposoma BV, Amsterdam, the Netherlands) has been widely used in many immunologic studies to selectively deplete macrophages with high efficiency ${ }^{28,29}$ To determine the effect of scleral macrophage depletion on FDM development, i.p. injection (described below) of liposomes containing CLOD (CLOD; $n=13$ ) or the control liposomes containing phosphate-buffered saline (PBS; LIP; $n=15$ ) were administered every 2 days for 2 weeks in 4 -week-old male wild-type mice. FDM was induced for 2 weeks beginning after the first 24 hours of CLOD or LIP injection. Ocular measurements were recorded before and after 2 weeks of FDM induction. Peripheral blood was drawn and prepared for flow cytometry, whereas the sclera was collected for F4/80 immunofluorescence labeling. CLOD treatment is highly efficacious in depleting liver macrophage content. ${ }^{30}$ Accordingly, the liver was used as a positive control to validate that CLOD-encapsulated liposome treatment has such an effect in this tissue. The assessment entailed performing F4/80 immunofluorescence staining to estimate declines in macrophage density in frozen sections of liver.

To assess the effect of fibroblast-specific $\mathrm{Ccl} 2$ deletion on normal refractive development, the ocular measurements were performed from P31 (week 4.5) to P73 (week 10.5) in both $C c l 2^{f / f l}$ mice $(n=22)$ and the scleral $S 100 a 4^{C r e} C c l 2^{f / f l}$ mice $(n=26)$. To assess the effect of fibroblast-specific $C c l 2$ deletion on FDM development, 2 weeks of FD were performed in $\mathrm{Ccl}^{f / / f}(n=16)$ and $\mathrm{S100a} 4^{\mathrm{Cre}} \mathrm{Ccl}^{f l / f l}(n=12)$ mice. FD treatment was initiated at 4.5 weeks of age. Untreated animals from $\mathrm{Ccl}^{\mathrm{flfl}}(n=8)$ and $5100 \mathrm{a} 4^{\mathrm{Cre}} \mathrm{Ccl} 2^{\mathrm{fl} / \mathrm{f}}$ $(n=11)$ served as the age-matched controls. Ocular measurements were recorded before and after 2 weeks of FD. The tissues obtained from these mice were prepared for RT-qPCR analysis of $\mathrm{Ccl} 2$ expression and immunofluorescence labeling of F4/80. In this case, the ocular measurements and the FDM induction in $5100 a 4^{C r e} \mathrm{Ccl}^{f / f l}$ mice were initiated at 4.5 weeks rather than 4 weeks of age. This delay was chosen because at 4 weeks of age, it was difficult to accurately measure their refraction. It is possible that this difficulty was encountered because $S 100 a 4^{C r e} C \mathrm{Cl} 2^{f / f l}$ mice had a lower body weight than the $C c l 2^{f l / f}$ mice (Supplemental Figure S2).

For experiments using the transgenic mice, both male and female mice were randomly distributed into treatment groups within each genotype.

\section{CLOD Administration and Flow Cytometry}

Macrophage depletion was achieved by i.p. injection of CLOD. CLOD $(50 \mathrm{mg} / \mathrm{kg}$ body weight $)$ or an equal volume of the control LIP was injected ${ }^{31} 24$ hours before FD, and then once every 2 days. To estimate the CLOD depletion efficiency, flow cytometry was used to monitor its effects on $\mathrm{CD} 45^{+} \mathrm{CD} 11 \mathrm{~b}^{+} \mathrm{CD} 115^{+}$monocyte densities in the peripheral blood, as previously described. ${ }^{32}$ Briefly, anticoagulated blood samples $(100 \mu \mathrm{L})$ from the two groups were incubated for 20 minutes at room temperature in the dark with rat anti-mouse CD45 peridinin-chlorophyll proteins-cyanine 5.5 (1:100; clone 30-F11; eBioscience, San 
Table 1 Primers for Quantitative Real-Time RT-PCR (RT-qPCR) and Genotype Identification

\begin{tabular}{|c|c|c|}
\hline Mouse gene & Forward primer & Reverse primer \\
\hline \multicolumn{3}{|l|}{ Primers for RT-qPCR } \\
\hline $18 \mathrm{~s}$ & $5^{\prime}$-CGGACACGGACAGGATTGAC-3' & 5'-GTTCAAGCTGCCCGTCTCCTCATC-3' \\
\hline Cd206 (Mrc1) & 5'-CTCTGTTCAGCTATTGGACGC-3' & 5'-CGGAATTTCTGGGATTCAGCTTC-3' \\
\hline Ccl2 & 5'-TTAAAAACCTGGATCGGAACCAA-3' & 5'-GCATTAGCTTCAGATTTACGGGT-3' \\
\hline Mcsf (Csf1) & 5'-GTGTCAGAACACTGTAGCCAC-3' & $5^{\prime}-$ TCAAAGGCAATCTGGCATGAAG- $3^{\prime}$ \\
\hline Ucp-1 (Ucp1) & 5'-AGGCTTCCAGTACCATTAGGT-3' & 5'-CTGAGTGAGGCAAAGCTGATTT-3' \\
\hline LysM $^{\text {Cre }} \mathrm{Mmp}-2^{\mathrm{fl} / \mathrm{fl}}$ & $5^{\prime}-$ TGCTGAAAGATACCCTCAAGAAGAT-3' & $5^{\prime}$-TATGTGATCTGGTTCTTGTCCCAC-3' \\
\hline $\mathrm{S} 100 \mathrm{a} 4^{\mathrm{Cre}} \mathrm{Ccl} 2^{f l / f l}$ & $5^{\prime}$-AGCAAGATGATCCCAATGAGTAGGC-3' & $5^{\prime}$-ACTACAGCTTCTTTGGGACACC-3' \\
\hline \multicolumn{3}{|c|}{ Primers for genotype identification of Lys $M^{\mathrm{Cre}} \mathrm{Mmp}-2^{\mathrm{fl} / \mathrm{fl}}$ and $M m p 2^{f l / f l}$ mice } \\
\hline $5^{\prime}$ LoxP & $5^{\prime}-$ ATACCAGGCACATAGAGGAGAGGTC- $3^{\prime}$ & 5'-GCTTCCTTGGGAATTGCCTTC-3' \\
\hline$S 100 a 4^{\text {Cre }}$ & 5'-GGATAGAGCACTTAAAATGGGGA-3' & 5'-GTGAAACAGCATTGCTGTCACTT-3' \\
\hline \multicolumn{3}{|c|}{ Primers for genotype identification of LysM ${ }^{\text {Cre }}$ Rosa26-stop-flox-tdTomato mice } \\
\hline Rosa26 & 5'-GGCATTAAAGCAGCGTATCC-3' & 5'-CTGTTCCTGTACGGCATGG-3' \\
\hline
\end{tabular}

Diego, CA), rat anti-mouse CD11b phosphatidylethanolamine (1:50; clone M1/70; BD Bioscience, San Jose, CA), and rat anti-mouse CD115-allophycocyanin (1:50; clone AFS98; eBioscience). Then, $1 \mathrm{~mL}$ of Erythrolyse Red Cell Lysing Buffer (BD Bioscience) was added, and the samples were incubated in the dark for 10 minutes at room temperature. After incubation, samples were centrifuged at 400 $\times g$ for 5 minutes, and the supernatants were discarded. Cell pellets were resuspended with $200 \mu \mathrm{L}$ cold PBS to achieve a concentration of $1 \times 10^{5}$ to $1 \times 10^{7}$ cells $/ \mathrm{mL}$. Cells were detected by a BD FACS ARIA II cell sorter (BD Bioscience) and analyzed using BD FACSDiva software version 6.1.3 (BD Bioscience).

\section{Image Analysis of Confocal Microscopy Immunofluorescence}

After different treatments, mice were sacrificed, and their eyes were enucleated. Frozen scleral sections were prepared, as previously described. ${ }^{6}$ Briefly, the cornea, conjunctiva, lens, and vitreous were removed and discarded. The remaining eyecup, including the retina, choroid, and sclera, was then fixed in freshly prepared $4 \%$ paraformaldehyde for 20 minutes at room temperature and dehydrated in an ascending series of $10 \%$ ( 2 hours), $20 \%$ ( 2 hours), and $30 \%$ (overnight) sucrose solutions at $4{ }^{\circ} \mathrm{C}$. The eyecups were then embedded in Neg 50 Frozen Section Medium (Thermo Fisher Scientific, Waltham, MA) and frozen in liquid nitrogen followed by storage at $-80^{\circ} \mathrm{C}$ before sectioning. The eyecups were cut into sections $(12 \mu \mathrm{m}$ thick) using a freezing microtome (Leica CM 1860 UV; Leica Microsystems, Solms, Germany). After rinsing the slides three times in PBS for 5 minutes each, a $0.1 \mathrm{~mol} / \mathrm{L}$ PBS blocking solution containing $6 \%$ normal donkey serum, $1 \%$ bovine serum albumin, and $0.3 \%$ Triton X-100 was applied for 2 hours at room temperature to block non-specific binding. Primary antibodies against F4/80 (1:200; ab6640; CI:A3-1; Abcam, Cambridge, UK) and MMP-2 (1:400; SC-10736; H-76; Santa Cruz Biotechnology, Dallas, TX) were diluted in the dilution buffer (containing 3\% normal donkey serum, $0.5 \%$ bovine serum albumin, and $0.3 \%$ Triton $\mathrm{X}-100$ in $0.1 \mathrm{~mol} / \mathrm{L}$ PBS), which covered the sections for overnight incubation at $4^{\circ} \mathrm{C}$. After washing the sections three times with PBS for 5 minutes each, they were incubated with secondary antibodies for 2 hours at room temperature with either donkey anti-rat IgG $(\mathrm{H}+\mathrm{L})$ conjugated to Alexa Fluor 488 (1:400; A-21208; Invitrogen, Carlsbad, CA) or donkey anti-rabbit IgG $(\mathrm{H}+\mathrm{L})$ conjugated to Alexa Fluor 555 (1:400; A-31572; Invitrogen). The secondary antibodies were diluted in the same solution as the primary antibody. Finally, cell nuclei were stained with DAPI (Vector Laboratories, Burlingame, CA). The frozen sections were visualized, and the images were captured with a Zeiss LSM 710 confocal microscope (ZEISS, Gottingen, Germany) or AXIO IMAGER Z1 microscope (ZEISS) under a $\times 20$ magnification objective. Negative controls were established by omitting the primary F4/80 and/or MMP-2 antibodies and processing the frozen scleral sections in the same manner as the other scleral sections. Supplemental Figure S3 shows the negative control images, in which there was an absence of F4/80 macrophage and/or MMP-2 staining.

Supplemental Figure S4 shows the posterior region (referring to the anatomic location; ie, closest to the posterior pole of the eye), which was subjected to cell counting of $\times 20$ imaging fields in stained scleral frozen sections. $\mathrm{F} 4 / 80^{+}$or tdTomato $^{+}$signal that overlapped with DAPI staining was 
assumed to be indicative of a macrophage in each image. The region of interest subjected to the image analysis encompassed the circumscribed area between the optic nerve and the scleral periphery. This delineation is relevant because we took into account the possibility that the scleral macrophage density in the posterior region may be different from that in the peripheral region. The region of interest for cell counting was outlined in each immunofluorescence image. The measurement of the region of interest area and the cell counting of the scleral macrophages were performed by utilizing the ImageJ software version 1.48 (NIH, Bethesda, MD; https:// imagej.nih.gov/ij). Three discontinuous sections from each eyeball were assessed in a blinded manner (Y.W., Y.L., and L.M.), and the average cell density was taken as the sample value. Data analyses were performed on groups each containing four to seven mice (Figures 2-6, 8, and 9, and Supplemental Figures S5 and S7).

\section{Gene Expression Analysis}

The Mmp2 mRNA expression levels in the sclera, retina, cornea, and lens of 10 -week-old $\mathrm{LysM}^{\mathrm{Cre}} \mathrm{Mmp}-2^{\mathrm{f} / \mathrm{fl}}$ and $M m p 2^{f / f l}$ mice were determined by RT-qPCR analysis. Such analysis also determined the time-dependent differential expression levels of $\mathrm{Mmp} 2$ and macrophage-related proteinencoding genes after $1,1.25,1.5,1.75,2,2.25,2.5,7$, and 14 days of FD induction in wild-type mice. Furthermore, this analysis determined $\mathrm{Ccl} 2 \mathrm{mRNA}$ expression levels in sclera, retina, cornea, and lens of 10.5-week-old $S 100 a 4^{C r e} \mathrm{Ccl}^{f l / f t}$ and $\mathrm{Ccl} 2^{f l / f}$ mice.

The sclera, cornea, and lens were dissected following eye enucleation. Subsequently, they were homogenized separately using a ball mill, and total RNA was extracted using the RNeasy Fibrous Tissue MiniKit (Qiagen, Hilden, Germany), according to the manufacturer's instructions. Total RNA from the retina was extracted using TRIZOL reagent (Invitrogen), according to the manufacturer's protocol. After treating with RQ1 RNase-Free DNase (Promega, Madison, WI), the RNAs were subjected to reverse transcription with random primers and M-MLV Reverse Transcriptase (Promega) to synthesize the respective cDNAs. ${ }^{33}$ RT-qPCR was performed using the specific primers and Power SYBR Green PCR Master Mix (Applied Biosystems, Foster City, CA) on an ABI ViiA 7 RealTime PCR system (Applied Biosystems). The expression level was determined with $\mathrm{C}_{\mathrm{T}}$ values and the $2_{\mathrm{T}}^{-\Delta \Delta \mathrm{C}}$ method. ${ }^{34}$ Each target mRNA was normalized relative to $18 \mathrm{~s}$ rRNA. Table 1 provides the sequences of the above-mentioned primers and those used specifically for $\mathrm{LysM}^{\mathrm{Cre}} \mathrm{Mmp}-2^{\mathrm{f} / / \mathrm{fl}}$ and

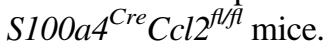

\section{Statistical Analysis}

All data were analyzed using statistics SPSS software 18.0 (IBM, Armonk, NY) or GraphPad Prism Software 8.3 (GraphPad Software Inc., San Diego, CA). The ShapiroWilk normality test was used to analyze the distribution of all data sets. For comparisons of two groups, independent data sets were compared by unpaired two-tailed $t$-tests or nonparametric $U$-tests. Multiple comparisons were performed using one-way analysis of variance (ANOVA) with Bonferroni post hoc tests, Kruskal-Wallis nonparametric with Dunn post hoc tests, or two-way ANOVA with Bonferroni post hoc tests. For multiple comparisons over time, a two-way repeated-measure ANOVA (RM-ANOVA) with Bonferroni post hoc tests was performed. Outlier test was performed on all the data by using the $3-\mathrm{SD}$ (means $\pm 3 \mathrm{SD}$ ) method. All the data were included in the statistical analysis. $P<0.05$ was considered statistically significant. For the statistical differences that are near $P=0.05$, a two-stage linear step-up procedure of Benjamini, Krieger, and Yekutieli was used to correct for multiple comparisons by controlling the false discovery rate.

\section{Results}

\section{FD Induces Increases in Scleral Macrophage Density}

To determine if changes in scleral macrophage content are associated with myopia development, the male wild-type C57BL/6 mice were subjected to FD for 2 weeks. At the end of this period, the scleral macrophage density in the FDtreated right eyes (FD-T) was compared with both the fellow non-FD left eyes (FD-F) and the normal control eyes of other age-matched mice not exposed to FD (normal).

Following this period, a significant myopic shift in refraction (two-way RM-ANOVA main effect of FD treatment: $F_{1,9}=9.961, P=0.005$, FD-T versus FD-F at 2 weeks of FD: $P=0.001)$ (Figure $1 \mathrm{~A})\left(F_{1,9}=6.438\right.$, $P=0.032$, FD versus control at 2 weeks of FD: $P=0.001$ ) (Figure 1B) accompanied AL elongation $\left(F_{1,9}=10.830, P=0.009, \mathrm{FD}\right.$ versus control at 2 weeks of FD: $P=0.007$ ) (Figure 1C). Although the VCD of FD-T eyes slightly increased relative to FD-F eyes $\left(F_{1,9}=0.935, P=0.359\right.$ ) (Figure 1D), this difference was not statistically significant. Consistent with the studies in the same field using mouse, ${ }^{26}$ guinea pig, ${ }^{35}$ and tree shew ${ }^{7}$ myopia models, the anterior chamber depth remained unchanged between the FD-T eyes and FD-F eyes during myopia development $\left(F_{1,9}=0.367, P=0.560\right)$ (Figure 1E), so the anterior chamber depth data was not presented in the following study. F4/80 immunofluorescence staining showed that the densities of $\mathrm{F} 4 / 80^{+}$macrophage were larger in the posterior region of the scleras in the FD-T eyes than those in the FD-F and normal eyes $\left(F_{2,14}=4.904, P=0.024\right.$; FD-T versus FD-F: $P=0.028$; FD-T versus normal: $P=0.012$; one-way ANOVA; FD-T versus FD-F versus normal: $9.007 \pm 0.794$ versus $6.545 \pm 0.704$ versus $5.972 \pm 0.655$ cells $/ 10,000 \mu \mathrm{m}^{2}$ ) (Figure 2, A and B). However, the staining patterns were not significantly different between the FD-F and normal eyes $(P=0.595$, one-way ANOVA) (Figure 2, A and B). 
To determine if macrophages affect scleral MMP-2 expression levels, MMP-2 and F4/80 were co-immunolabeled in FD-treated mice (Figure 2A). Accompanying the increased density of scleral $\mathrm{F} 4 / 80^{+}$macrophages (Figure $2 \mathrm{~B}$ ), the density of scleral cells co-expressing MMP-2 and F4/80 $(P=0.006$, Kruskal-Wallis test; FD-T versus FD-T: $1.834 \pm 0.304$ versus $0.932 \pm 0.076$ cells $/ 10,000 \mu \mathrm{m}^{2}, P=0.011$ ) (Figure 2C) in the FD-T eyes was higher than in the FD-F eyes. The ratio of scleral cells co-expressing MMP- 2 and F4/80 among the F4/80 ${ }^{+}$cells in FD-F eyes was slightly higher than in the FD-F eyes; however, this difference was not statistically significant $\left(F_{2,14}=1.455, P=0.267\right.$; FD-T versus FD-F: $0.211 \pm 0.035$ versus $0.149 \pm 0.020, P=0.111$; one-way ANOVA) (Figure 2D).

To assess the time course of changes in scleral macrophage density during myopia development, FD was performed for 2 days, 1 week, or 2 weeks in LysM ${ }^{\text {Cre }}$ Rosa $26^{\mathrm{f} / / \mathrm{fl}}$ mice. After 2 days of FD, there were no significant differences in the density of scleral tdTomato $^{+}$cells $\left(F_{2,11}=1.294\right.$, $P=0.313$; FD-T versus FD-F versus normal: $6.282 \pm 0.842$ versus $4.550 \pm 0.928$ versus $6.276 \pm 0.887$ cells $/ 10,000$ $\mu \mathrm{m}^{2}$; FD-T versus FD-F: $P=0.183$; FD-T versus normal: $P=0.996$; FD-F versus normal: $P=0.209$; one-way ANOVA) (Supplemental Figure S5A), F4/80 ${ }^{+}$cells $\left(F_{2,14}=3.298, P=0.076\right.$; FD-T versus $\mathrm{FD}-\mathrm{F}$ versus normal: $8.801 \pm 0.822$ versus $6.709 \pm 0.515$ versus $8.858 \pm 0.658$ cells $/ 10,000 \mu \mathrm{m}^{2} ;$ FD-T versus normal: $P=0.955$; FD-F versus normal: $P=0.053$; one-way ANOVA) (Supplemental Figure S5B), or double-labeled scleral cells $\left(F_{2,14}=1.262, P=0.321\right.$; FD-T versus FD$\mathrm{F}$ versus normal: $5.468 \pm 0.737$ versus $3.711 \pm 0.963$ versus $5.262 \pm 0.907$ cells $/ 10,000 \mu \mathrm{m}^{2}$; FD-T versus FD-F: $P=0.167$; FD-T versus normal: $P=0.874$; FD-F versus normal: $P=0.247$; one-way ANOVA) (Supplemental Figure S5C) among the FD-T, FD-F, and normal groups, except the density of scleral $\mathrm{F} 4 / 80^{+}$cells in FD-T eyes was higher than in the FD-F eyes (FD-T versus FD-F: $P=0.047$; one-way ANOVA) (Supplemental Figure S5B).

After 1 week of FD, significant myopia was induced in the LysM $^{\mathrm{Cre}}{ }^{\mathrm{Rosa}} 6^{\mathrm{f} / \mathrm{fl}}$ mice (two-way RM-ANOVA main effect of FD treatment: $F_{1,8}=1.766, P=0.221$, FD-T versus FDF at 1 week of FD: $P=0.008$ ) (Supplemental Figure S6A) $\left(F_{1,8}=1.471, P=0.2598\right.$; FD versus control at 1 week of FD: $P=0.032$ ) (Supplemental Figure S6B). The densities of scleral tdTomato ${ }^{+}$cells $\left(F_{2,14}=5.585, P=0.019\right.$; FD-T versus FD-F versus normal: $10.07 \pm 1.168$ versus $7.034 \pm 0.460$ versus $6.788 \pm 0.469$ cells $/ 10,000 \mu \mathrm{m}^{2}$; FD-T versus FD-F: $P=0.017$; FD-T versus normal: $P=0.011$; FD-F versus normal: $P=0.826$; one-way ANOVA) (Supplemental Figure S7A), F4/80 $0^{+}$cells $\left(F_{2,14}=4.230\right.$, $P=0.041$; FD-T versus FD-F versus normal: $13.49 \pm 0.642$ versus $9.956 \pm 1.143$ versus $10.42 \pm 0.948$ cells $/ 10,000$ $\mu^{2}$; FD-T versus FD-F: $P=0.020$; FD-T versus normal: $P=0.038$; FD-F versus normal: $P=0.732$; one-way ANOVA) (Supplemental Figure S7B), and double-labeled cells were higher in the FD-T eyes than in the FD-F and normal eyes $\left(F_{2,14}=5.238, P=0.023\right.$; FD-T versus FD-F versus normal: $8.737 \pm 1.066$ versus $5.691 \pm 0.496$ versus $5.698 \pm 0.622$ cells $/ 10,000 \mu \mathrm{m}^{2}$; FD-T versus FD-F: $P=0.016$; FD-T versus normal: $P=0.016$; FD-F versus normal: $P=0.995$; one-way ANOVA) (Supplemental Figure S7C).

After 2 weeks of FD, significant myopia was induced in the LysM $^{\mathrm{Cre}} \mathrm{Rosa} 26^{\mathrm{t} / \mathrm{fl}}$ mice (two-way RM-ANOVA main effect of FD treatment: $F_{1,9}=1.401, P=0.267$, FD-T versus FD-F at 1 week of FD: $P=0.001$ ) (Supplemental Figure S8A) $\left(F_{1,9}=4.279, P=0.069\right.$, FD versus control at 1 week of FD: $P=0.005$ ) (Supplemental Figure S8B). However, there were no significant changes in AL elongation $\left(F_{1,9}=0.061, P=0.810\right)$ (Supplemental Figure S8C) or VCD increase $\left(F_{1,9}=0.220, P=0.651\right)$ (Supplemental Figure S8D). The density of scleral tdTomato ${ }^{+}$cells was higher in FD-T eyes than in FD-F eyes $\left(F_{2,13}=2.826\right.$, $P=0.096$; FD-T versus FD-F: $4.604 \pm 0.645$ versus $2.746 \pm 0.583$ cells $/ 10,000 \mu \mathrm{m}^{2}, P=0.042$; one-way ANOVA) (Figure 3, A and B). The density of scleral F4/ $80^{+}$cells was slightly higher in FD-T eyes than in FD-F eyes $\left(F_{2,13}=1.985, \quad P=0.178 ; \quad\right.$ FD-T versus FD-F: $7.480 \pm 1.216$ versus $4.759 \pm 0.906$ cells $/ 10,000 \mu \mathrm{m}^{2}$; $P=0.068$; one-way ANOVA) (Figure 3, A and C); however, there was no statistical significance. The density of scleral double-labeled cells was slightly higher in FD-T eyes than in FD-F eyes $\left(F_{2,13}=3.140, P=0.077\right.$; FD-T versus FD-F: $3.452 \pm 0.517$ versus $0.951 \pm 0.453$ cells $/ 10,000$ $\mu \mathrm{m}^{2} ; P=0.041$; one-way ANOVA) (Figure 3, A and D). Nevertheless, there were no significant differences in labeled cell densities between FD-T and normal eyes (tdTomato ${ }^{+}$ cells: $P=0.730 ; \mathrm{F} 4 / 80^{+}$cells: $P=0.405$; double-labeled cells: $P=0.951$; one-way ANOVA) (Figure 3) or between the FD-F and normal eyes (tdTomato $^{+}$cells: $P=0.119$; F4 $/ 80^{+}$cells: $P=0.374$; double-labeled cells: $P=0.071$; one-way ANOVA) (Figure 3).

Taken together, there is a correspondence between increases in scleral macrophage density and MMP-2 upregulation during myopia development.

\section{Partial Scleral Macrophage Depletion by CLOD Induces a Hyperopic Shift}

Because circulating blood monocytes are a source of tissue macrophages ${ }^{36}$ it was determined if they are a source of the increases in scleral macrophages during myopia development. Accordingly, liposomes containing CLOD were injected into the i.p. space to reduce the monocyte content. ${ }^{37}$ Compared with the mice injected with LIP vehicle, the ratio of $\mathrm{CD}_{4} 5^{+} \mathrm{CD} 11 \mathrm{~b}^{+} \mathrm{CD} 115^{+}$immunostained monocytes in the peripheral blood 24 hours after receiving the CLOD injections was significantly lower $\left(F_{2,10}=65.54\right.$, $P<0.001$; CLOD versus LIP: $P<0.001,0.005 \pm 0.004$ versus $0.140 \pm 0.012$; one-way ANOVA) (Supplemental Figure S9, A and B). Surprisingly, the ratio of $\mathrm{CD} 45^{+} \mathrm{CD} 11 \mathrm{~b}^{+} \mathrm{CD} 115^{+}$monocytes was significantly 
higher in the peripheral blood of LIP-injected mice than in noninjected normal mice (normal versus LIP: $0.085 \pm 0.010$ versus $0.140 \pm 0.012, P=0.006$; one-way ANOVA) (Supplemental Figure S9, A and B). On the other hand, there was a significant reduction in the density of liver F4/ $80^{+}$-immunostained macrophages in CLOD-injected mice compared with noninjected and LIP-injected mice (Supplemental Figure S9C).

After 2 weeks of either CLOD or LIP injections and exposure to FD, the density of scleral macrophages in the FD-T eyes of CLOD-injected mice was significantly lower than in FD-T eyes of the LIP-injected mice (two-way ANOVA main effect of CLOD treatment: $F_{1,16}=13.80$, $P=0.002$; CLOD versus LIP: $7.885 \pm 0.7641$ versus $10.57 \pm 0.5203$ cells $/ 10,000 \mu \mathrm{m}^{2}, P=0.011$ ) (Figure 4, A and B). In addition, the density of scleral macrophages in FD$\mathrm{F}$ eyes of CLOD-injected mice was lower than in FD-F eyes of the LIP-injected mice $(P=0.008$; CLOD versus LIP: $7.885 \pm 0.7641$ versus $10.57 \pm 0.5203$ cells $/ 10,000 \mu \mathrm{m}^{2}$, $P=0.011$ ) (Figure 4, A and B). Furthermore, there was no significant difference in the density of macrophages between the FD-T and FD-F eyes of the CLOD-injected mice or between the FD-T and FD-F eyes of the LIP-injected mice (two-way ANOVA main effect of FD treatment: $F_{1,16}=0.293, P=0.596$; CLOD-injected mice, $P=0.536$; LIP-injected mice, $P=0.896$ ) (Figure $4, \mathrm{~A}$ and $\mathrm{B}$ ).

After 2 weeks of FD, significant myopia was induced in both the CLOD and LIP-injected groups (two-way RMANOVA main effect of FD treatment: $F_{1,26}=124.4$, $P<0.0001$ ) (Figure 4C), accompanied by AL elongation $\left(F_{1,26}=5.367 P=0.029\right)$ (Figure $\left.4 \mathrm{D}\right)$. Although a slight increase in VCD was observed, this difference was not statistically significant $\left(F_{1,26}=3.449, P=0.075\right)$ (Figure 4E). Interestingly, both the FD-T and FD-F eyes of the CLOD-injected mice experienced a relative hyperopic shift in refraction compared with their respective counterparts (FD-T and FD-F eyes) of the LIP-injected control mice (two-way ANOVA main effect of CLOD treatment: $F_{1,52}=26.75, P<0.0001$; for FD-T: CLOD versus LIP: $-2.261 \pm 1.073$ versus $-7.232 \pm 0.880 \mathrm{D}, P=0.002$; for FD-F: CLOD versus LIP: $5.377 \pm 0.830$ versus $0.813 \pm 0.832 \mathrm{D}, P=0.006$ ) (Figure 4F). Consistent with the change in refraction, the increases in $\mathrm{AL}\left(F_{1,52}=13.2\right.$, $P=0.0006$; for FD-T: CLOD versus LIP: $0.123 \pm 0.008$ versus $0.165 \pm 0.013 \mathrm{~mm}, P=0.026$; for FD-F: CLOD versus LIP: $0.111 \pm 0.008$ versus $0.140 \pm 0.011 \mathrm{~mm}$, $P=0.219)$ (Figure $4 \mathrm{G})$ and $\operatorname{VCD}\left(F_{1,52}=9.676\right.$, $P=0.003$; for FD-T: CLOD versus LIP: $-0.023 \pm 0.007$ versus $0.010 \pm 0.009 \mathrm{~mm}, P=0.045$; for FD-F: CLOD versus LIP: $-0.031 \pm 0.008$ versus $-0.012 \pm 0.009 \mathrm{~mm}$, $P=0.674$ ) (Figure $4 \mathrm{H}$ ) in FD-T and FD-F eyes of the CLOD-injected mice were attenuated compared with those in their respectively counterparts (FD-T and FD-F eyes) of LIP-injected animals.

Taken together, these results indicate that declines in scleral macrophage densities modulated the refractive development in both normal and vision-obstructed environments (FD-induced environment in the current study). On the other hand, they did not affect the magnitude of the myopic shift induced by FD.

\section{Macrophage-Specific Mmp2 Deletion Reduces FDM Development}

Macrophage-specific Mmp2 deletion mice (LysM ${ }^{\mathrm{Cre}} \mathrm{Mmp}-$ $2^{\mathrm{f} / \mathrm{fl}}$ ) were used to determine if macrophage-derived MMP-2 up-regulation contributes to myopia progression. The immunofluorescence data revealed that both the density $\left(\mathrm{LysM}^{\mathrm{Cre}} \mathrm{Mmp}-2^{\mathrm{fl} / \mathrm{fl}}\right.$ versus $\mathrm{Mmp} 2^{\mathrm{fl} / f l}: 0.7252 \pm 0.130$ versus $1.873 \pm 0.265$ cells $/ 10,000 \mu \mathrm{m}^{2}, P=0.003$, unpaired $t$ test) (Figure 5, A and B) and the ratio (LysM ${ }^{\mathrm{Cre}} \mathrm{Mmp}-2^{\mathrm{f} / \mathrm{fl}}$ versus $M m p 2^{f l f f}: 0.109 \pm 0.016$ versus $0.247 \pm 0.015$ cells/ $10,000 \mu^{2} ; P<0.001$, unpaired $t$-test) (Figure 5, A and C) of $\mathrm{MMP}^{+} 2^{+}$macrophages among the total macrophage population were lower in $\mathrm{LysM}{ }^{\mathrm{Cre}} \mathrm{Mmp}-2^{\mathrm{ff} / \mathrm{fl}}$ mice than in the $M m p 2^{f / f l}$ mice. However, the scleral Mmp2 mRNA levels were not different between $\mathrm{LysM}{ }^{\mathrm{Cre}} \mathrm{Mmp}-2^{\mathrm{f} / / \mathrm{fl}}$ and $M m p 2^{f l / f}$ mice $(P=0.065 ; U$-tests) (Figure 5D). In addition, Mmp2 mRNA expression levels in the retina, lens, and cornea were not different between these two genotypes (retina: $P=0.609$; lens: $P=0.655$; cornea: $P=0.867 ; U$ tests) (Figure 5D).

The effect of macrophage-specific Mmp2 deletion on normal refractive development was first determined. Although hyperopia developed in LysM ${ }^{\mathrm{Cre}} \mathrm{Mmp}-2^{\mathrm{f} / \mathrm{fl}}$ and $M m p 2^{f / f l}$ mice from P28 to P70 (4 to 10 weeks) in a normal visual environment, the LysM ${ }^{\mathrm{Cre}} \mathrm{Mmp}-2^{\mathrm{f} / / \mathrm{fl}}$ mice were less hyperopic than $M m p 2^{f l / f}$ mice (two-way RM-ANOVA main effect of genotype: $F_{1,45}=4.405, P=0.042 ; 4$ weeks: $-4.771 \pm 1.006$ versus $-4.842 \pm 0.6977 \mathrm{D} ; 5$ weeks: $-1.900 \pm 0.8842$ versus $-0.2100 \pm 0.7020 \mathrm{D} ; 6$ weeks: $-1.733 \pm 0.9970$ versus $0.0429 \pm 0.7038 \mathrm{D} ; 8$ weeks: $-1.733 \pm 0.9970$ versus $2.555 \pm 0.9376 \quad \mathrm{D} ; 10$ weeks: $1.412 \pm 1.073$ versus $2.262 \pm 0.8666 \mathrm{D}$ ) (Figure 5E). There were no significant differences in $\operatorname{AL}\left(F_{1,45}=2.184, P=0.1464 ; 4\right.$ weeks: $2.611 \pm 0.0073$ versus $2.634 \pm 0.0083 \mathrm{~mm} ; 6$ weeks: $2.740 \pm 0.0076$ versus $2.757 \pm 0.0061 \mathrm{~mm}$; 8 weeks: $2.818 \pm 0.0062$ versus $2.823 \pm 0.0055 \mathrm{~mm} ; 10$ weeks: $2.855 \pm 0.0063$ versus $2.856 \pm 0.0057 \mathrm{~mm})$ (Figure $5 \mathrm{~F})$ or $\operatorname{VCD}\left(F_{1,45}=0.982, P=0.327\right.$; 4 weeks: $0.7468 \pm 0.0042$ versus $0.7424 \pm 0.0052 \mathrm{~mm} ; 6$ weeks: $0.7048 \pm 0.0028$ versus $0.7015 \pm 0.0041 \mathrm{~mm} ; 8$ weeks: $0.6642 \pm 0.01517$ versus $0.6629 \pm 0.0029 \mathrm{~mm} ; 10$ weeks: $0.6351 \pm 0.0047$ versus $0.6297 \pm 0.0031 \mathrm{~mm}$ ) (Figure 5G) at any time between $\mathrm{Mmp} 2^{\mathrm{flff}}$ and $\mathrm{LysM} \mathrm{Cre}^{\mathrm{Cre}} \mathrm{Mmp}-2^{\mathrm{t} / \mathrm{fl}}$ mice.

Next, it was determined if macrophage-specific Mmp2 deletion could inhibit myopia progression. $\mathrm{LysM}^{\mathrm{Cre}} \mathrm{Mmp}-2^{\mathrm{fl} / \mathrm{fl}}$ and $M m p 2^{f / / f}$ mice underwent FD for 4 weeks. After this period, both the density (two-way ANOVA effect of FD treatment: $F_{1,20}=5.067, P=0.0358$; FD-T versus FD-F: $3.663 \pm 0.872$ versus $1.597 \pm 0.321$ cells $/ 10,000 \mu \mathrm{m}^{2}$, $P=0.034)$ (Figure 6, A and B) and ratio $\left(F_{1,20}=41.77\right.$, 
$P<0.001 ;$ FD-T versus FD-F: $0.463 \pm 0.074$ versus $0.255 \pm 0.032, P=0.011$ ) (Figure $6, \mathrm{~A}$ and $\mathrm{C}$ ) of scleral MMP $-2^{+} \mathrm{F} 4 / 80^{+}$colabeled cells among the total macrophage population were higher in the FD-T eyes than in the FD-F eyes in the $\mathrm{Mmp} 2^{f / f /}$ mice. These increases in MMP- $2^{+} \mathrm{F} 4 / 80^{+}$cells in the FD-T eyes were not observed in LysM ${ }^{\mathrm{Cre}} \mathrm{Mmp}-2^{\mathrm{f} / \mathrm{fl}}$ mice (density: FD-T versus FD-F: $0.0660 \pm 0.111$ cells $/ 10,000 \mu \mathrm{m}^{2}$ versus $0.608 \pm 0.102$ cells $/ 10,000 \mu \mathrm{m}^{2}, P>0.9999$; ratio: FD$\mathrm{T}$ versus FD-F: $0.085 \pm 0.006$ cells $/ 10,000 \mu \mathrm{m}^{2}$ versus $0.105 \pm 0.007$ cells $/ 10,000 \mu \mathrm{m}^{2}, P>0.9999$ ) (Figure 6, A-C). Furthermore, both the density (two-way ANOVA main effect of genotype: $F_{1,20}=18.00, P=0.0004 ;$ LysM ${ }^{\mathrm{Cre}} \mathrm{Mmp}-2^{\mathrm{fl} / \mathrm{fl}}$ versus $M m p 2^{f l f l} ; P=0.001$ ) (Figure $6, \mathrm{~A}$ and B) and the ratio $\left(F_{1,20}=41.77, \quad P<0.0001 ; \quad\right.$ LysM ${ }^{\mathrm{Cre}} \mathrm{Mmp}-2^{\mathrm{f} / \mathrm{fl}}$ versus $M m p 2^{f f / f}: P=0.001$ ) (Figure 6, A and C) of the MMP $-2^{+} \mathrm{F} 4 / 80^{+}$colabeled cells were lower in the FD-T eyes of LysM ${ }^{\mathrm{Cre}} \mathrm{Mmp}-2^{\mathrm{fl} / \mathrm{fl}}$ mice than in the FD-T eyes of Mmp $2^{f l / f}$ mice.

After 4 weeks of FD, significant myopia was induced in both LysM ${ }^{\mathrm{Cre}} \mathrm{Mmp}-2^{\mathrm{f} / \mathrm{fl}}$ and $M m p 2^{f / f f}$ mice (two-way RM-ANOVA main effect of FD treatment: $F_{1,54}=1.121, P=0.274$; left versus right, for LysM ${ }^{\mathrm{Cre}} \mathrm{Mmp}-2^{\mathrm{fl} / \mathrm{fl}}, P<0.001$, for $M m p 2^{f / f l}$, $P<0.001$ ) (Figure 6D). However, the myopia induced in $\mathrm{LysM}^{\mathrm{Cre}} \mathrm{Mmp}-2^{\mathrm{A} / \mathrm{fl}}$ mice was significantly less than that in $M m p 2^{f l f l}$ mice (two-way ANOVA main effect of genotype: $F_{1,54}=13.236, P<0.001 ; \mathrm{LysM}^{\mathrm{Cre}} \mathrm{Mmp}-2^{\mathrm{t} / \mathrm{fl}}$ versus $M m p 2^{f f / f}:-3.756 \pm 0.5722$ versus $-9.807 \pm 1.1013 \mathrm{D}$, $P<0.001$ ) (Figure 6E). AL elongation was inhibited in the FD-treated LysM ${ }^{\mathrm{Cre}} \mathrm{Mmp}-2^{\mathrm{f} / \mathrm{fl}}$ mice compared with the FD-treated $M m p 2^{f / f f l}$ mice $\left(F_{1,54}=0.276, P=0.602\right.$; LysM $^{\mathrm{Cre}} \mathrm{Mmp}-2^{\mathrm{f} / \mathrm{fl}}$ versus Mmp $2^{f / f f}: 0.0048 \pm 0.0059$ versus $0.0402 \pm 0.0169 \mathrm{~mm}, P=0.019$ ) (Figure 6F). Increases in VCD were slightly inhibited in the FD-treated $\mathrm{LysM}^{\mathrm{Cre}} \mathrm{Mmp}$ $2^{\mathrm{f} / \mathrm{fl}}$ mice compared with the FD-treated $M m p 2^{f / f l}$ mice, but the difference was not significant $\left(F_{1,54}=0.015, P=0.904\right.$; LysM ${ }^{\mathrm{Cre}} \mathrm{Mmp}-2^{\mathrm{f} / \mathrm{fl}}$ versus Mmp $2^{\text {flfff: }}: 0.0045 \pm 0.0045$ versus $0.02492 \pm 0.0122 \mathrm{~mm}, P=0.054$ ) (Figure 6G).

Taken together, these results indicate that macrophagespecific Mmp2 deletion significantly suppressed FDM development, which suggests that macrophage-derived MMP-2 up-regulation contributes to myopia progression.

\section{Circulating Blood Monocytes Are a Source of Scleral Macrophages in Myopic Eyes}

Tissue macrophage content is dependent on both infiltration of circulating blood monocytes and IL-4-induced increases in tissue resident macrophage proliferation. Monocyte infiltration is mediated through CCL2 binding to the C-C chemokine receptor- 2 on the surface of monocytes. As a result of such interaction, sites are exposed, allowing macrophage colony-stimulating factor 1 (MCSF) and IL-13 to induce monocytes to differentiate into macrophages. ${ }^{38}$ In addition, monocyte- and tissue-derived macrophages are distinguishable from one another on the basis of differences in distinct gene expression patterns. ${ }^{39}$ The mannose receptor, CD206 (MRC1), is a well-defined marker of monocyte-derived macrophages, whereas uncoupling protein 1 (UCP-1) is a specific marker of tissue-derived macrophages.

It was first determined if these above-mentioned scleral gene expression changes follow a circadian rhythm across a single day (3:00 AM, 9:00 AM, 3:00 PM, and 9:00 PM) in wildtype C57BL/6J mice. The same analysis of circadian rhythmicity of mRNA levels of scleral Mmp2 was also performed because its up-regulation contributed to myopia development. ${ }^{6}$ RT-qPCR analysis showed that there were no significant changes in scleral mRNA expression levels of all these genes, except for Ill3, across a single day (Mmp2: $F_{3,24}=0.273, P=0.844 ; C c l 2: F_{3,24}=0.580, P=0.634$; Mcsf (Csfl): $P=0.473$; Ill3: $F_{3,24}=3.269, P=0.039$; $\mathrm{Cd} 206$ (Mrcl): $\quad F_{3,24}=1.975, \quad P=0.145 ; \quad I l 4:$ $F_{3,24}=0.831, \quad P=0.490 ;$ one-way ANOVA) (Supplemental Figure S10). To more clearly delineate if diurnal rhythms preceded or occurred in response to FDM progression, age-matched mice were used without FD stimulus (labeled as normal group) (Figure 7) at each time point as the control.

To determine the relative contribution made by each of these two sources to increases in scleral macrophage density during myopia progression, RT-qPCR analysis of the time course $(1,1.25,1.5,1.75,2,2.25,2.5,7$, and 14 days of FD induction) (Figure 7A) of changes in the expression levels of scleral Ccl2, Mcsf (Csf1), and Il-13 (Il13), which are known to affect monocyte infiltration, and $\mathrm{Cd} 206$ (Mrcl) was performed. In parallel, RT-qPCR analysis was used to evaluate Il-4 (Il4) expression levels because it modulates tissue resident macrophage proliferation and Ucp-1 (Ucpl). Furthermore, these studies accompanied measurements of scleral Mmp2 mRNA levels.

\section{Scleral Mmp2 Expression}

No significant differences were observed in Mmp2 mRNA expression among normal, FD-F, and FD-T groups after 1, 1.25, 1.5, and 1.75 days of FD induction (Figure 7B). After 2 days of FD, a significant difference appeared between FD$\mathrm{T}$ and normal eyes $\left(F_{2,36}=4.363, P=0.020\right.$; FD-T versus normal: $P=0.017$, one-way ANOVA). This higher expression in FD-T eyes disappeared after 2.25 and 2.5 days of FD. After 1 or 2 weeks of FD, the Mmp2 mRNA expression was higher in FD-T eyes than in normal eyes (1 week: $F_{2,31}=5.581, P=0.009$, FD-T versus normal eyes: $P=0.007$, one-way ANOVA; 2 weeks: FD-T versus normal eyes: $P=0.043$, Kruskal-Wallis test).

\section{Scleral Ccl2 Expression}

The scleral $C c l 2$ expression was higher in FD-T eyes than in normal eyes after 1 or 1.25 days of FD ( 1 day, FD-T versus normal eyes: $P=0.044$, Kruskal-Wallis test; 1.25 days, $F_{2,30}=10.11, P=0.0004$, FD-T versus normal eyes: $P=0.0004$, one-way ANOVA) (Figure 7C). This increase disappeared at 1.5 and 1.75 days of FD. After 2 or 2.25 days 

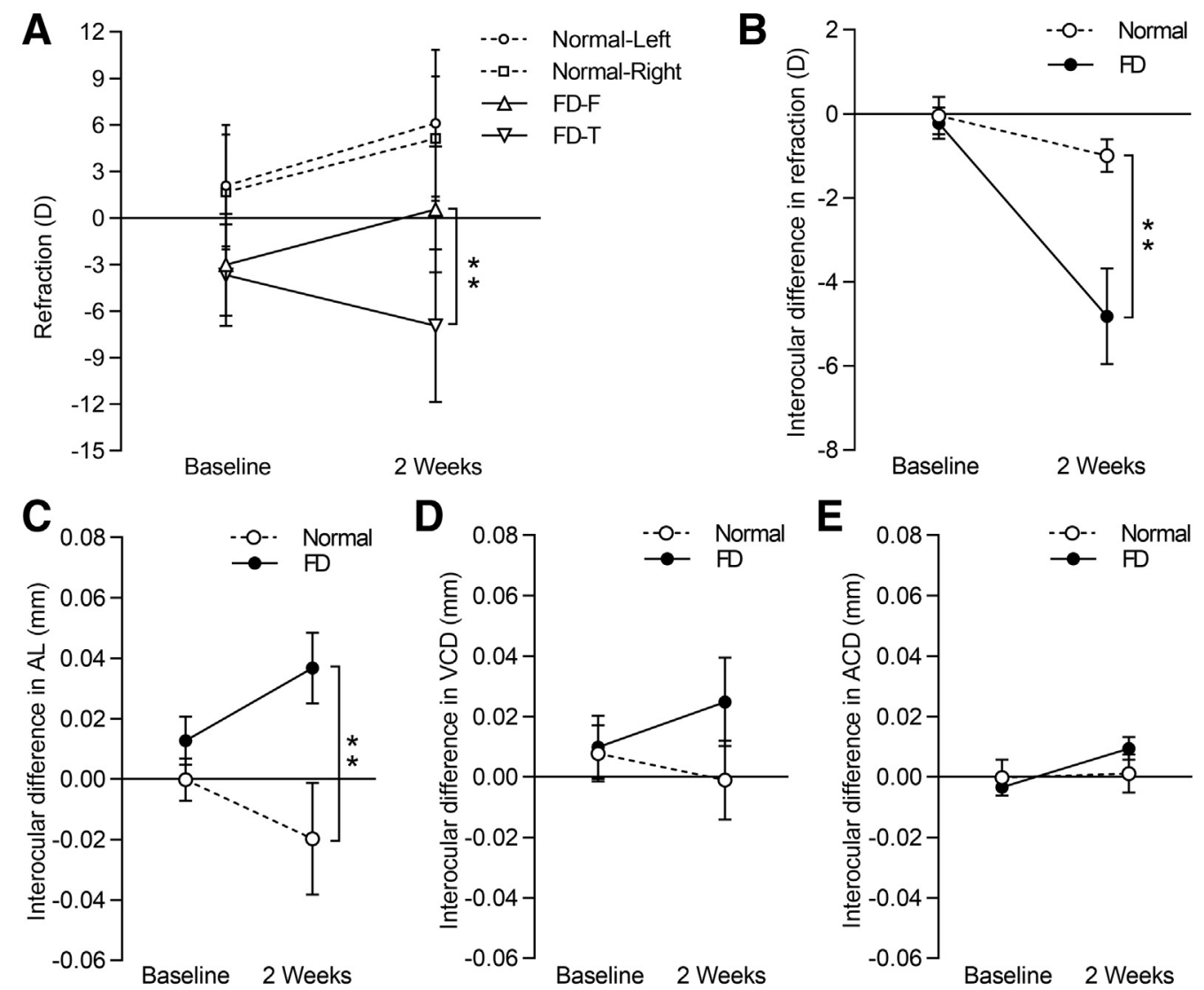

Figure 1 Two weeks of form-deprivation (FD) induces significant myopia in wild-type mice. A: After 2 weeks of FD, significant myopia is induced in FDtreated right eyes (FD-T) eyes compared with the untreated left fellow eyes (FD-F) eyes. B-E: Interocular differences (value for FD-T/right eyes minus that for FD-F/left eyes) in refraction (B), axial length (AL; C), vitreous chamber depth (VCD; D), and anterior chamber depth (ACD; E). Baseline indicates before FD, and 2 weeks indicates 2 weeks after FD. Data are expressed as means \pm SEM $(\mathbf{A}-\mathbf{E}) . n=5$ normal mice $(\mathbf{A}-\mathbf{E}) ; n=6 \mathrm{FD}$ mice $(\mathbf{A}-\mathbf{E})$. ${ }^{* *} P<0.01(\mathrm{a}$ two-way repeated-measure analysis of variance with Bonferroni post hoc test). $D$, diopter; normal-left, left eyes in normal mice; normal-right, right eyes in normal mice.

of FD, $C c l 2$ expression was higher in FD-T eyes than in both the FD-F and/orn eyes (2 days, FD-T versus FD-F eyes: $P=0.041$, FD-T versus normal eyes: $P=0.004$, KruskalWallis test; 2.25 days, FD-T versus FD-F eyes: $P=0.069$, FD-T versus normal eyes: $P=0.030$, one-way ANOVA). Then, this increase disappeared at 2.5 days of FD. After 1 week of FD, $C c l 2$ expression was higher in FD-T eyes than in both the FD-F and the normal eyes $\left(F_{2,31}=10.33\right.$, $P=0.0004$, FD-T versus FD-F eyes: $P=0.002$, FD-T versus normal eyes: $P=0.001$, one-way ANOVA). Then, this increase disappeared at 2 weeks of FD.

\section{Scleral Mcsf (Csf1) Expression}

The scleral Mcsf (Csfl) expression was higher in FD-T eyes than in normal eyes after 1.25 days of $\mathrm{FD}\left(F_{2,31}=5.528\right.$, $P=0.009$; FD-T versus normal eyes: $P=0.0098$, one-way ANOVA) (Figure 7D). This increase disappeared at 1.5 and 1.75 days of FD. After 2 or 2.25 days of FD, Mcsf (Csfl) expression was higher in FD-T eyes than in normal or FD-F eyes ( 2 days, FD-T versus normal eyes: $P=0.019$, Kruskal-Wallis test; 2.25 days, $F_{2,31}=2.129, P=0.136$; FD-T versus FD-F eyes: $P=0.049$, one-way ANOVA). Then, this increase disappeared at 2.5 days of FD. After 1 or 2 weeks of FD, the Mcsf (Csfl) mRNA expression was higher in FD-T eyes than in FD-F and/or normal eyes (1 week, FD-T versus FD-F eyes: $P=0.033$, FD-T versus normal eyes: $P=0.003$, Kruskal-Wallis test; 2 weeks, $F_{2,41}=2.995$, $P=0.061$, FD-T versus FD-F eyes: $P=0.386$, FD-T versus normal eyes: $P=0.021$, one-way ANOVA).

\section{Scleral Il13 Expression}

The $I l 13$ expression level was higher in FD-T eyes than in normal eyes as early as after 1 day of FD $\left(F_{2,33}=5.627\right.$, $P=0.008$, FD-T versus normal eyes: $P=0.002$ ) (Figure 7E). This increase disappeared at 1.25, 1.5, and 1.75 days of FD. After 2, 2.25, or 2.5 days of FD, the $I l 13$ expression level in FD-T eyes was higher than in normal or FD-F eyes ( 2 days: FD-T versus FD-F: $P=0.016$, KruskalWallis test; 2.25 days: $F_{2,41}=4.834, P=0.015$, FD-T versus normal: $P=0.004$, one-way ANOVA; 2.5 days: FD-T versus normal: $P=0.031$, Kruskal-Wallis test). This higher expression level disappeared at 7 or 14 days of FD.

\section{Scleral Cd206 (Mrc1) Expression}

The Cd206 (Mrcl) expression was higher in FD-T eyes than in normal eyes after 1.5 days of $\mathrm{FD}\left(F_{2,31}=7.236, P=0.003\right.$; 
A
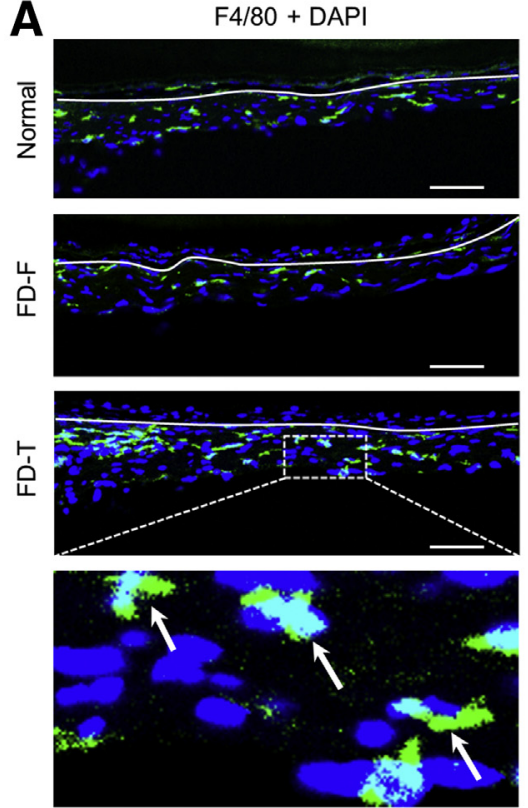

B

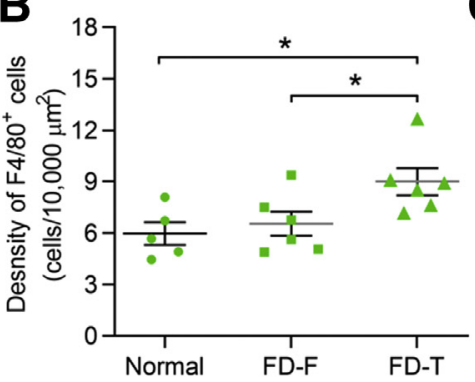

F4/80 + MMP-2
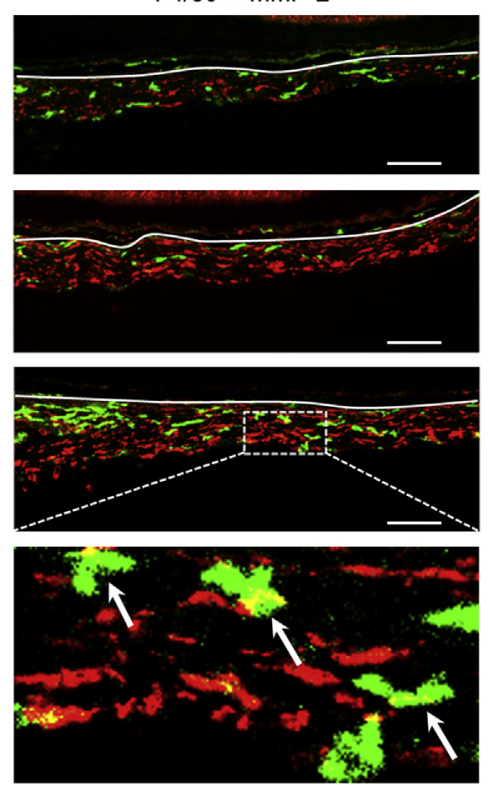

C

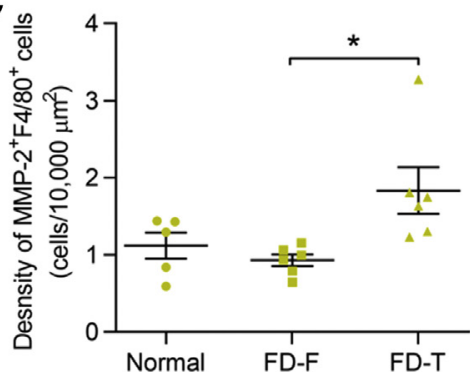

$F 4 / 80+M M P-2+D A P I$
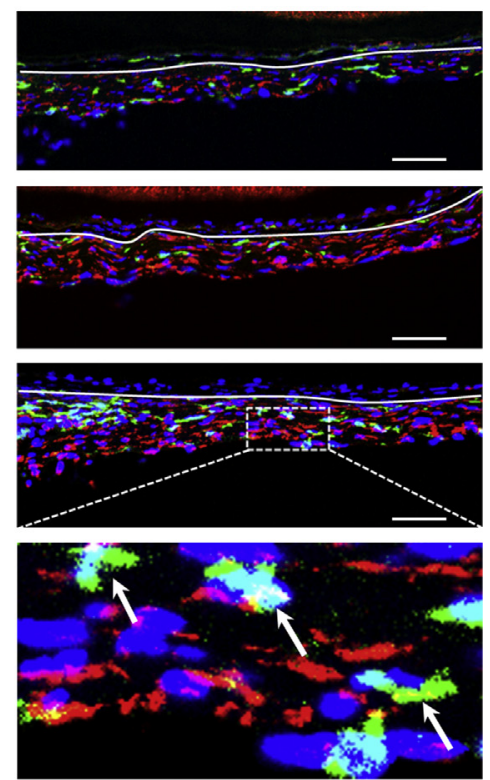

D

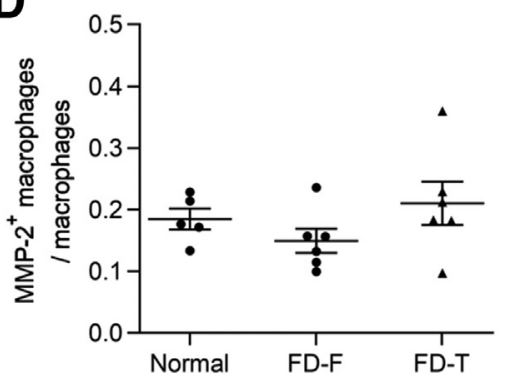

Figure 2 Form-deprivation (FD)-induced increases in scleral macrophage density accompany matrix metallopeptidase 2 (MMP-2) up-regulation. A: Representative images depicting $\mathrm{F} 4 / 80^{+}$signal with DAPI nuclear staining (first column; green + blue), $\mathrm{F} 4 / 80^{+} \mathrm{MMP}^{+} 2^{+}$signals (second column; green + red), and F $4 / 80^{+}$MMP $-2^{+}$signals with DAPI nuclear staining (third column; green + red + blue) after 2 weeks of FD. The bottom row shows the detailed magnification of the sclera, and the arrows in the first column point to the same cells shown in the second and third columns. White solid lines indicate scleral margin to the choroid. B: The density of scleral macrophages in FD eyes is higher than in fellow nondeprived eyes and age-matched normal eyes. C: The density of scleral MMP-2 $2^{+}$macrophages is higher in the FD-treated eyes (FD-T) group than in untreated fellow eyes (FD-F) group. Data comparisons were assessed by Kruskal-Wallis nonparametric test with Dunn post hoc tests. D: The ratio of MMP- $2^{+}$macrophages among the total macrophage population in normal, FD-F, and FD-T eyes. Each data point represents an independent mouse (B-D). Data are expressed as means \pm SEM (B-D). $n=5$ normal mice (B-D); $n=6 \mathrm{FD}$ mice (B-D). ${ }^{*} P<0.05$ (one-way analysis of variance with Bonferroni post hoc tests). Scale bars $=50 \mu \mathrm{m}(\mathbf{A})$.

FD-T versus FD-F: $P=0.002$, FD-T versus normal: $P=0.047$, one-way ANOVA) (Figure 7F). This increase disappeared at 1.75 days of FD. After 2 days of FD, Cd206 (Mrcl) expression in FD-T eyes was higher than in normal eyes $\left(F_{2,31}=3.063, P=0.059\right.$; FD-T versus normal: $P=0.027$, one-way ANOVA). This increase disappeared at 2.25 days of FD. After 2.5, 7, and 14 days of FD, Cd206 (Mrcl) expression in FD-T eyes was higher than in normal or/and FD-F eyes (2.5 days: $F_{2,30}=3.153, P=0.057$, FD$\mathrm{T}$ versus normal: $P=0.043 ; 7$ days: $F_{2,31}=11.38$, $P=0.0002$, FD-T versus normal eyes: $P=0.0002$, FD-T versus FD-F eyes: $P=0.009 ; 14$ days: $F_{2,41}=8.419$, $P=0.0009$, FD-T versus normal eyes: $P=0.0002$, FD-T versus FD-F eyes: $P=0.018$; one-way ANOVA).

However, UCP-1 expression was undetectable in scleras from all three groups. Scleral Il-4 (Il4) expression remained unchanged in the three groups at all time points of FD induction (Figure 7G). Intriguingly, the up-regulation of $\mathrm{Ccl} 2$ and Cd206 (Mrcl) occurred earlier than changes in Mmp2 expression, whose increases were apparent after 2 days of FD. This time difference suggests that FD-induced increases in the density of scleral macrophages preceded MMP-2 up-regulation. In addition, none of these genes underwent up-regulation in the retinas of FD-T eyes (Supplemental Figure S11), indicating that monocyte-derived macrophage-related genes were up-regulated in the sclera rather than the retina.

Taken together, these results indicate that circulating monocytes are a source of increases in scleral macrophages during myopia progression.

\section{Loss of Fibroblast Ccl2 Function Attenuates FDM}

Fibroblasts are the major scleral cell type. To validate that increases in the density of scleral macrophages are mainly 

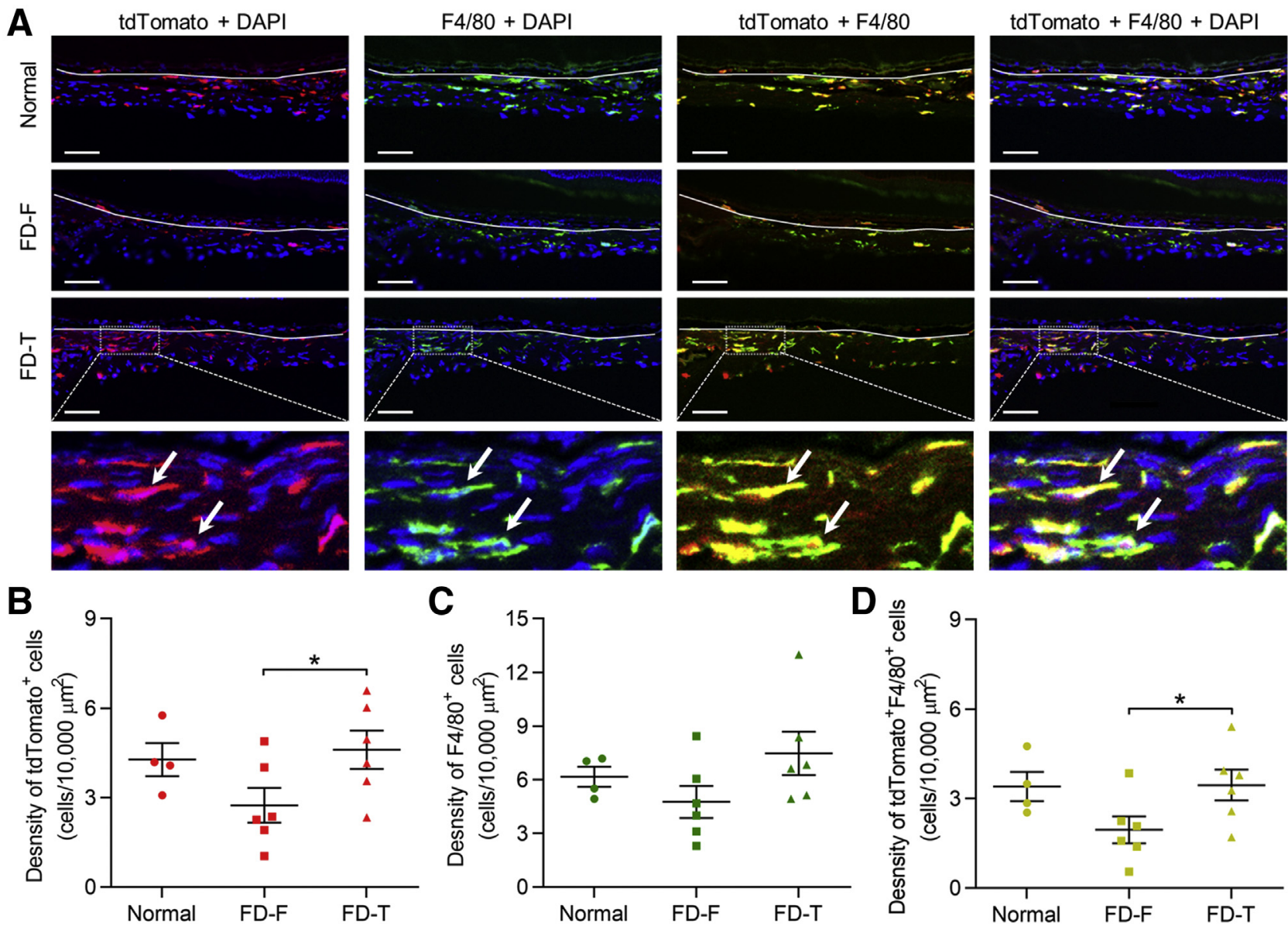

Figure 3 Increases in scleral macrophage density in Lys $\mathrm{M}^{\mathrm{Cre}}$ Rosa2 $6^{\mathrm{fl} / \mathrm{fl}}$ mice after 2 weeks of form-deprivation (FD). A: Representative images depicting tdTomato $^{+}$signals with DAPI nuclear staining (first column; red + blue), $F 4 / 80^{+}$signals with DAPI nuclear staining (second column; green + blue), tdTomato ${ }^{+} \mathrm{F}_{4} / 80^{+}$signals (third column; yellow in the merged images), and tdTomato ${ }^{+} \mathrm{F} 4 / 80^{+}$signals with DAPI nuclear staining (fourth column; red + green + blue) after 2 weeks of FD. The bottom row shows the detailed magnification of the sclera, and the arrows in the first column point to the same cells shown in the second, third, and fourth columns. White solid lines indicate scleral margin to the choroid. B-D: Densities of tdTomato ${ }^{+}$cells $(\mathbf{B}), \mathrm{F} / 80^{+}$ cells (C), and tdTomato ${ }^{+} \mathrm{F} 4 / 80^{+}$cells (D) in the scleras in normal, untreated fellow (FD-F) and FD-treated (FD-T) eyes. Each data point represents an independent mouse (B-D). Data are expressed as means \pm SEM (B-D). $n=4$ normal mice (B-D); $n=7$ FD mice (B-D). * $P<0.05$ (one-way analysis of variance with Bonferroni post hoc tests). Scale bars $=50 \mu \mathrm{m}(\mathbf{A})$.

derived from CCL2-induced promotion of monocyte recruitment, a fibroblast-specific $\quad C c l 2$ deletion $\left(\mathrm{S} 100 \mathrm{a} 4^{\mathrm{Cre}} \mathrm{Ccl} 2^{\mathrm{fl} / \mathrm{fl}}\right)$ mouse model was established. $S 100 a 4^{C r e} C_{C l} 2^{f l f l}$ mice had a lower body weight than $C c l 2^{f / f l}$ mice (Supplemental Figure S2) (two-way RM-ANOVA main effect of genotype: $F_{1,46}=7.365, P=0.009 ; 4.5$ weeks: $13.26 \pm 0.35 \mathrm{~g}$ versus $14.28 \pm 0.45 \mathrm{~g} ; 5.5$ weeks: $15.74 \pm 0.36 \mathrm{~g}$ versus $17.44 \pm 0.36 \mathrm{~g} ; 6.5$ weeks: $17.48 \pm 0.46 \mathrm{~g}$ versus $19.15 \pm 0.46 \mathrm{~g} ; 8.5$ weeks: $19.45 \pm 0.56 \mathrm{~g}$ versus $20.72 \pm 0.47 \mathrm{~g} ; 10.5$ weeks: $20.74 \pm 0.52 \mathrm{~g}$ versus $22.68 \pm 0.49 \mathrm{~g}$ ). Scleral $C c l 2 \mathrm{mRNA}$ expression was $91.8 \%$ lower in $\mathrm{S100a} 4^{\mathrm{Cre}} \mathrm{Ccl} 2^{\mathrm{fl} / \mathrm{fl}}$ mice than that in the $C c l 2^{f / f f}$ mice $(P<0.001, U$-tests) (Figure $8 \mathrm{~A})$. A similar decline also occurred in the lens, but not in the retina or cornea (retina: $P=0.217$, lens: $P<0.001$, cornea: $P=0.661 ; U$-tests) (Figure 8A). No significant difference was observed in lens thickness between these two genotypes (main effect of genotype: $F_{1,46}=0.643, P=0.427$; $1.486 \pm 0.0050$ versus $1.476 \pm 0.0054 \mathrm{~mm}$ for 4.5 weeks;
$1.592 \pm 0.0051$ versus $1.586 \pm 0.0036 \mathrm{~mm}$ for 6.5 weeks; $1.664 \pm 0.0045$ versus $1.662 \pm 0.3332 \mathrm{~mm}$ for 8.5 weeks; $1.716 \pm 0.0044$ versus $1.714 \pm 0.0026 \mathrm{~mm}$ for 10.5 weeks) (Figure 8B), suggesting that this reduction in lens $\mathrm{Ccl} 2$ expression had no significant effect on refraction. The scleral macrophage density was similar in $\mathrm{S1OOa} 4^{\mathrm{Cre}} \mathrm{Ccl} 2^{f l f l}$ and $C c l 2^{f / f l}$ mice at the posterior region of the sclera $\left(S 100 a 4^{C r e} C_{c l} 2^{f l / f l}\right.$ versus $C c l 2^{f l / f}: 7.893 \pm 0.954$ versus $7.002 \pm 1.042$ cells $/ 10,000 \mu \mathrm{m}^{2}, P=0.551$, unpaired $t$-test) (Figure 8, C and D).

The effects of scleral $C c l 2$ knockdown on normal refractive development were first determined. Although the refractive development increased in both genotypes from P32 to P73 ( 4.5 to 10.5 weeks) under a normal visual environment, the refraction of $S 100 \mathrm{a} 4^{\mathrm{Cre}} \mathrm{Ccl} 2^{\mathrm{flfl}}$ mice was relatively myopic than that of the $C c l 2^{f l / l}$ mice (two-way RM-ANOVA main effect of genotype: $F_{1,46}=16.26, P=0.0002 ; 4.5$ weeks: $-3.327 \pm 0.9248$ versus $-0.5018 \pm 0.8695 \mathrm{D}$; 5.5 weeks: $-1.373 \pm 0.8247$ versus $2.195 \pm 0.6529 \mathrm{D}$; 
A
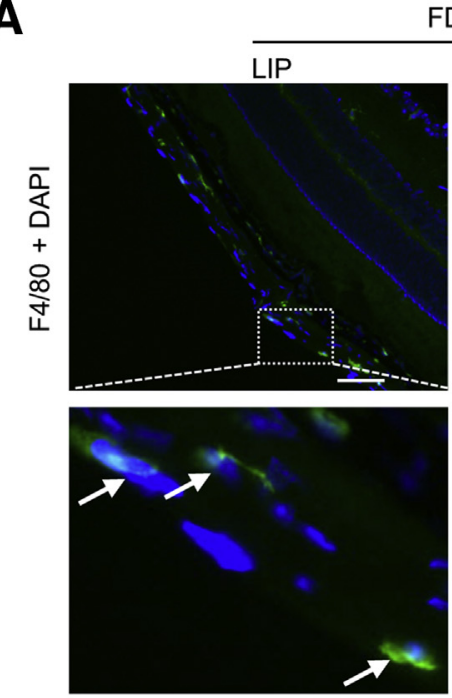

B

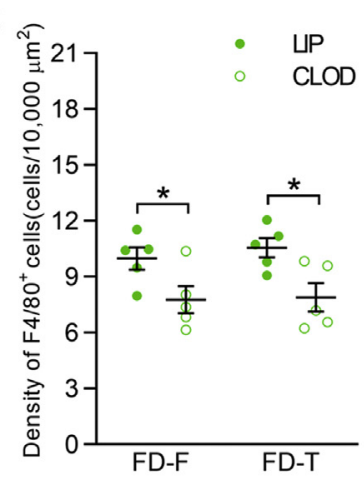

FD-F
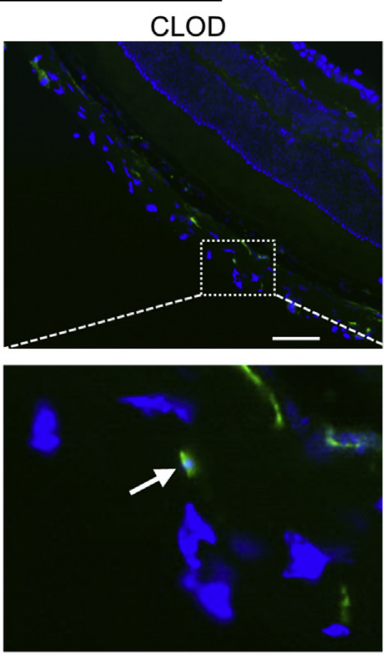

C

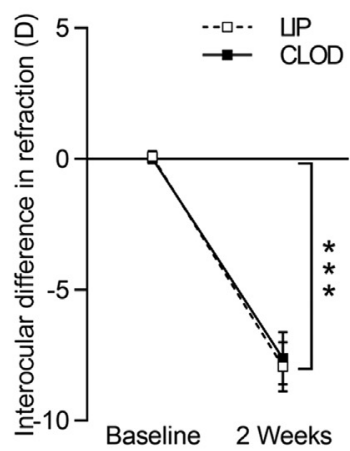

D
FD-T
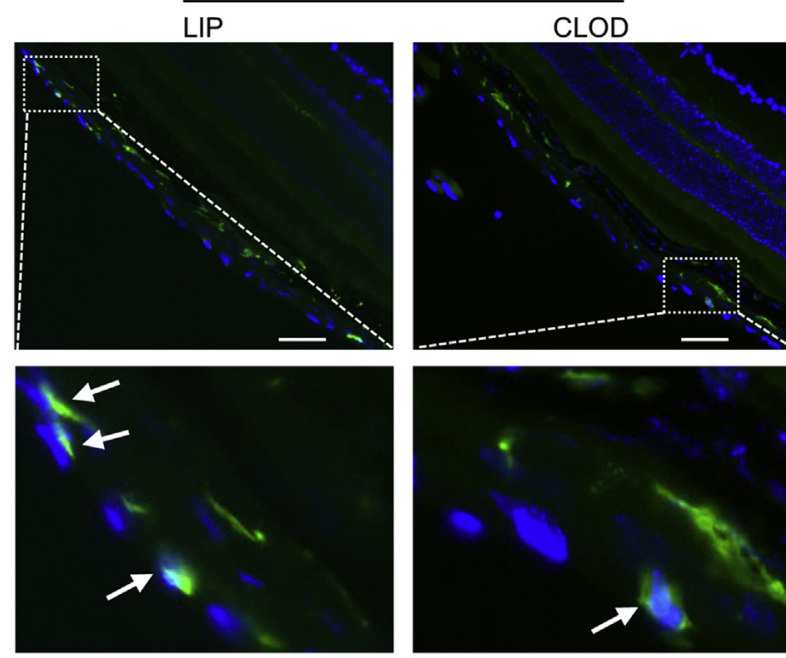

$\mathbf{E}$
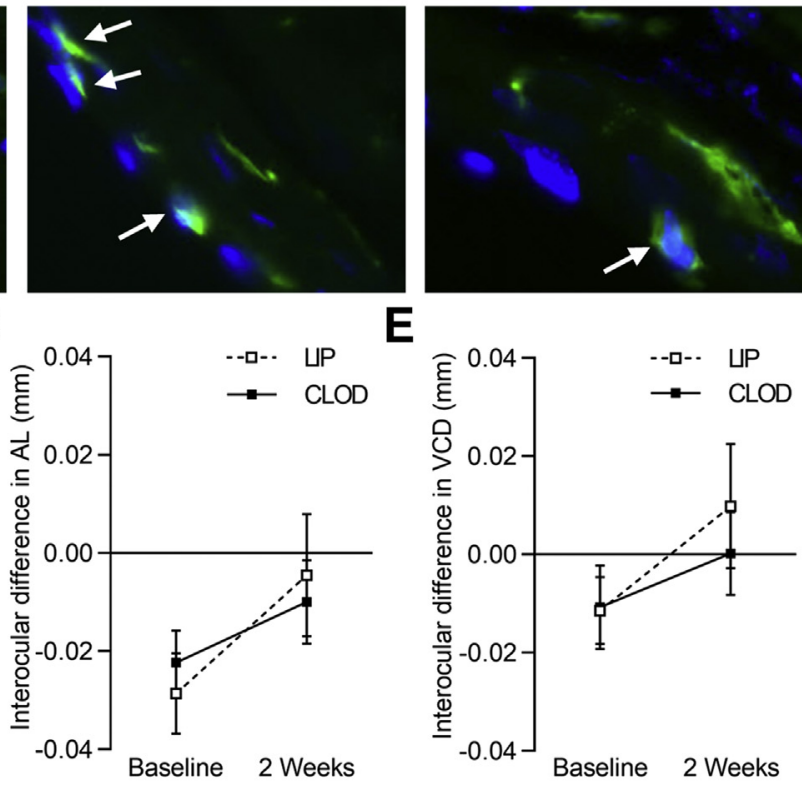

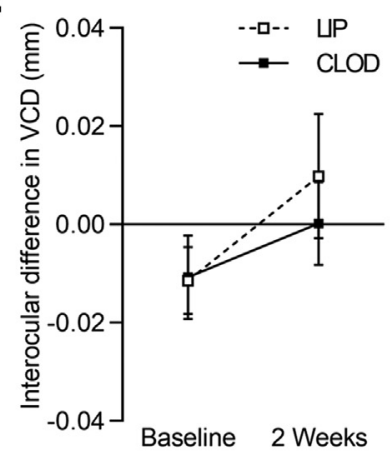

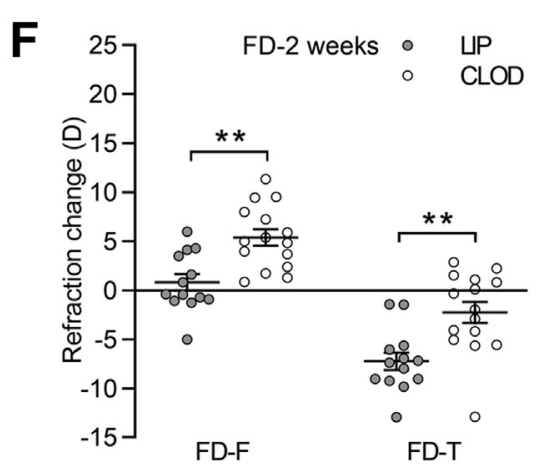
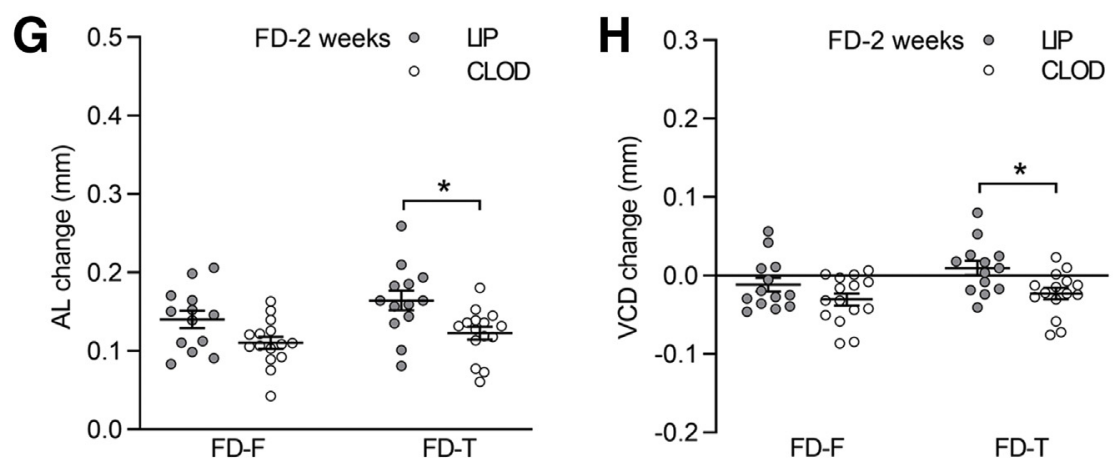

Figure 4 Clodronate (CLOD) injections reduce scleral macrophage density and contribute to a hyperopic shift in both the form-deprivation (FD)-treated (FD-T) and untreated fellow (FD-F) eyes. A: Representative images showing F4/80 immunolabeled macrophages with DAPI nuclear staining (first row; green + blue) of scleral sections after 2 weeks of FD and control liposomes containing phosphate-buffered saline (LIP) or CLOD injection. The second row shows the detailed magnification of the sclera, and the arrows point to $\mathrm{F} 4 / 80^{+}$macrophages. B: CLOD injection reduces the density of scleral $\mathrm{F} 4 / 80^{+}$ macrophages in FD-F and FD-T eyes. C-E: Interocular differences (FD-T eyes minus FD-F eyes) in refraction (C), axial length (AL; D), and vitreous chamber depth (VCD; E) for LIP (control) and CLOD-injected mice. F: Compared with the refraction before 2 weeks of FD induction, both FD-F and FD-T eyes undergo a significant hyperopic shift in response to CLOD in comparison to LIP injection. $\mathbf{G}$ and $\mathbf{H}$ : AL elongation and VCD increase in FD-T eyes and FD-F eyes after 2 weeks of FD induction. Each data point represents an independent mouse. Data in $\mathbf{B}$ and $\mathbf{F}-\mathbf{H}$ were analyzed using a two-way analysis of variance with Bonferroni post hoc tests, and data in $\mathbf{C}-\mathbf{E}$ were analyzed using a two-way repeated-measure analysis of variance with Bonferroni post hoc tests. Data are expressed as means \pm SEM $(\mathbf{B}-\mathbf{H}) . n=5$ mice for each group $(\mathbf{B}) ; n=13 \operatorname{LIP}(\mathbf{C}-\mathbf{H}) ; n=15 \operatorname{CLOD}(\mathbf{C}-\mathbf{H}) .{ }^{*} P<0.05,{ }^{* *} P<0.01$, and ${ }^{* * *} P<0.001$. Scale bars $=50 \mu \mathrm{m}(\mathbf{A})$. D, diopter.

6.5 weeks: $-1.008 \pm 0.7973$ versus $3.146 \pm 0.6806 \mathrm{D} ; 8.5$ weeks: $-0.287 \pm 1.028$ versus $3.824 \pm 0.9134 \mathrm{D}$ 10.5 weeks: $-1.349 \pm 1.025$ versus $2.562 \pm 0.9248 \mathrm{D})$ (Figure 8E). However, there were no significant differences in
AL (two-way RM-ANOVA interaction effect: $F_{3,188}=5.646, P=0.001$, main effect of genotype: $F_{1,46}=1.403, P=0.242 ; 4.5$ weeks: $2.666 \pm 0.0086$ versus $2.661 \pm 0.0065 \mathrm{~mm}$; 6.5 weeks: $2.791 \pm 0.0087$ versus 

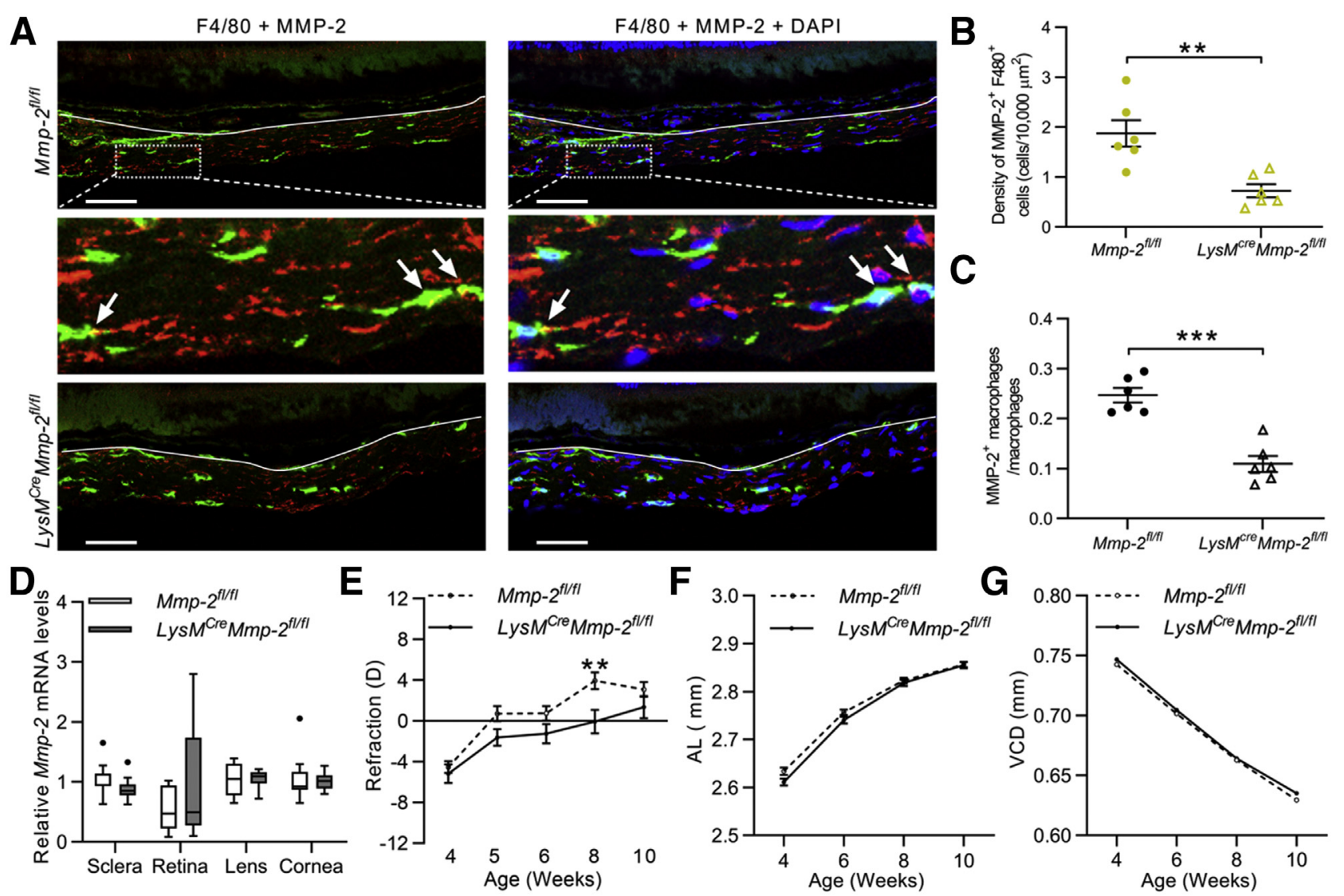

Figure 5 Retardation of refractive development in macrophage-specific Mmp2 deletion (Lys $\mathrm{M}^{\mathrm{Cre}} \mathrm{Mmp}-2^{\mathrm{fl} / \mathrm{fl}}$ ) mice. A: Representative images depicting $\mathrm{F} 4 /$ $80^{+} \mathrm{MMP}-2^{+}$signals (left column; green + red) and MMP $-2^{+} \mathrm{F} 4 / 80^{+}$signals with DAPI nuclear staining (right column; green + red + blue) of scleral sections. The middle row shows the detailed magnification of the sclera, and the arrows in the first column point to the same cells shown in the second column. White

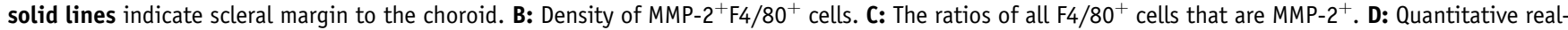
time RT-PCR (RT-qPCR) analysis of Mmp2 mRNA expression levels. Mmp2 expression levels were normalized to those of $M m p 2^{f l f l}$, and $18 \mathrm{~s} r R N A$ was used as the reference gene. $\mathbf{E}-\mathbf{G}$ : Refraction $(\mathbf{E})$, axial length $(\mathrm{AL} ; \mathbf{F})$, and vitreous chamber depth $(\mathrm{VCD} ; \mathbf{G})$ of $M m p 2^{f l f l}$ mice and LysM $\mathrm{M}^{\mathrm{Cre}} \mathrm{Mmp}-2^{\mathrm{fl} / \mathrm{fl}}$ mice at the indicated time points during normal refractive development. Data in $\mathbf{B}-\mathbf{D}$ were analyzed using unpaired two-tailed $t$-tests or nonparametric $\mathbf{U}$-tests, and data in $\mathbf{E}-\mathbf{G}$ were analyzed using a two-way repeated-measure analysis of variance with Bonferroni post hoc tests. Each data point represents an independent mouse (B and C). Box-plot diagrams showing the distribution of the data; lines within the boxes indicate medians; bars, range; black dots, outliers (D). Data are expressed

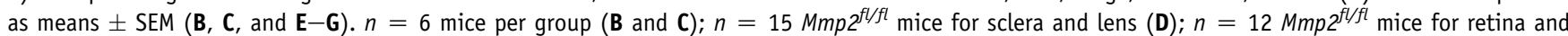
LysM $^{\mathrm{Cre}} \mathrm{Mmp}-2^{\mathrm{fl} / \mathrm{fl}}$ mice for sclera and lens (D); $n=13 \mathrm{Mmp}^{\mathrm{fl} / f l}$ mice for cornea (D); $n=11 \mathrm{LysM}^{\mathrm{Cre}} \mathrm{Mmp}-2^{f l / f l}$ mice for retina and cornea (D); $n=25 \mathrm{Mmp}-2^{f l / f l}$ mice $(\mathbf{E}-\mathbf{G}) ; n=22$ LysMCreMmp-2fl/fl mice $(\mathbf{E}-\mathbf{G}) .{ }^{*} P<0.05,{ }^{*} P<0.01$, and ${ }^{* *}{ }^{*} P<0.001$. Scale bars $=50 \mu \mathrm{m}(\mathbf{A})$. D, diopter.

$2.764 \pm 0.0060 \mathrm{~mm} ; 8.5$ weeks: $2.842 \pm 0.0082$ versus $2.829 \pm 0.0066 \mathrm{~mm} ; 10.5$ weeks: $2.875 \pm 0.0068$ versus $2.874 \pm 0.0055 \mathrm{~mm}$ ) (Figure $8 \mathrm{~F}$ ) or VCD (two-way RM-ANOVA interaction effect: $F_{3,188}=3.453, P=0.018$, main effect of genotype: $F_{1,46}=0.314, P=0.578 ; 4.5$ weeks: $0.7127 \pm 0.0045$ versus $0.7220 \pm 0.0037 \mathrm{~mm}$; 6.5 weeks: $0.6860 \pm 0.0037$ versus $0.6799 \pm 0.0045 \mathrm{~mm} ; 8.5$ weeks: $0.6464 \pm 0.0041$ versus $0.6481 \pm 0.0037 \mathrm{~mm}$; 10.5 weeks: $0.6193 \pm 0.0034$ versus $0.6247 \pm 0.0033 \mathrm{~mm}$ ) (Figure 8G), except for a small interocular difference in AL at week $6.5(P=0.041)$ (Figure $8 \mathrm{~F})$.

To determine if scleral $C c l 2$ knockdown suppressed scleral monocyte recruitment and myopia development, 2 weeks of FD were performed in $S 100 a 4^{\mathrm{Cre}} \mathrm{Ccl} 2^{\mathrm{flfl}}$ and $C c l 2^{f / f l}$ mice. After this period, the density of $\mathrm{F} 4 / 80^{+}$cells in FD-T eyes was larger than in FD-F eyes of $C c l 2^{f l / f}$ mice (two-way ANOVA effect of FD treatment: $F_{1,12}=5.180$,
$P=0.042 ;$ FD-T versus FD-F: $8.293 \pm 0.742$ versus $5.561 \pm 0.305$ cells $/ 10,000 \mu \mathrm{m}^{2}, P=0.013$ ) (Figure 9, A and B). However, this increase did not develop in $\mathrm{S} 100 \mathrm{a}{ }^{\mathrm{Cre}} \mathrm{Ccl}^{\mathrm{flfl}}$ mice (FD-T versus FD-F: $5.091 \pm 0.578$ versus $5.573 \pm 0.414$ cells $\left./ 10,000 \mu \mathrm{m}^{2}, P>0.9999\right)$ (Figure 9, A and B). Furthermore, the density of the F4/80 cells was significantly lower in the FD-T eyes of $S 100 a 4^{C r e} C_{c l} 2^{f l f l}$ mice compared with FD-T eyes of $C c l 2^{f l f l}$ mice (two-way ANOVA main effect of genotype: $F_{1,12}=10.19, P=0.008 ; S 100 a 4^{C r e} C c l 2^{f l / f l}$ versus $C c l 2^{f l}$ $\left.f_{1}: P=0.004\right)$ (Figure 9, A and B).

After 2 weeks of FD, significant myopia was induced in $\mathrm{Ccl}^{\mathrm{flfl}}$ mice but not in $\mathrm{S100a4}{ }^{\mathrm{Cre}} \mathrm{Ccl} 2^{f / f l}$ mice (two-way RMANOVA main effect of FD treatment: $F_{1,43}=1.139$, $P=0.292$; left versus right eyes: for $C c l 2^{f l f f}: P<0.001$, for S100a $4^{\mathrm{Cre} C} \mathrm{Cll}^{\mathrm{flfl}} P=0.262$ ) (Figure 9C). The amount of myopia induction in $\mathrm{S1OOa4}{ }^{\mathrm{Cre}} \mathrm{Ccl} 2^{f / H}$ mice was significantly 
A
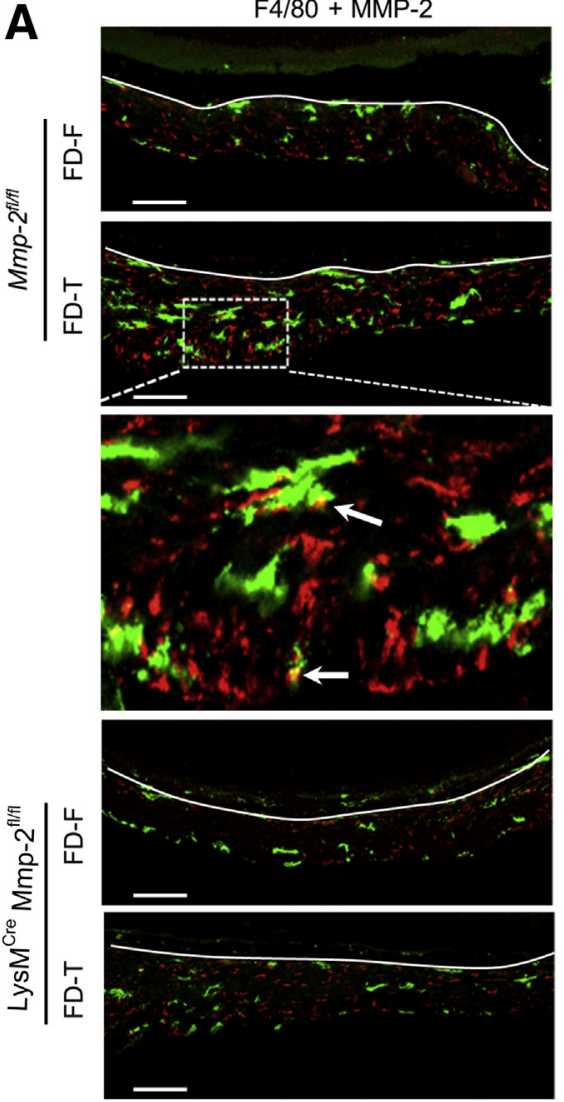

E

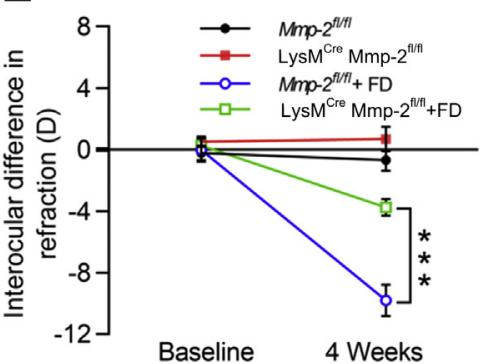

$\mathrm{F} 4 / 80+\mathrm{MMP}-2+\mathrm{DAPI}$
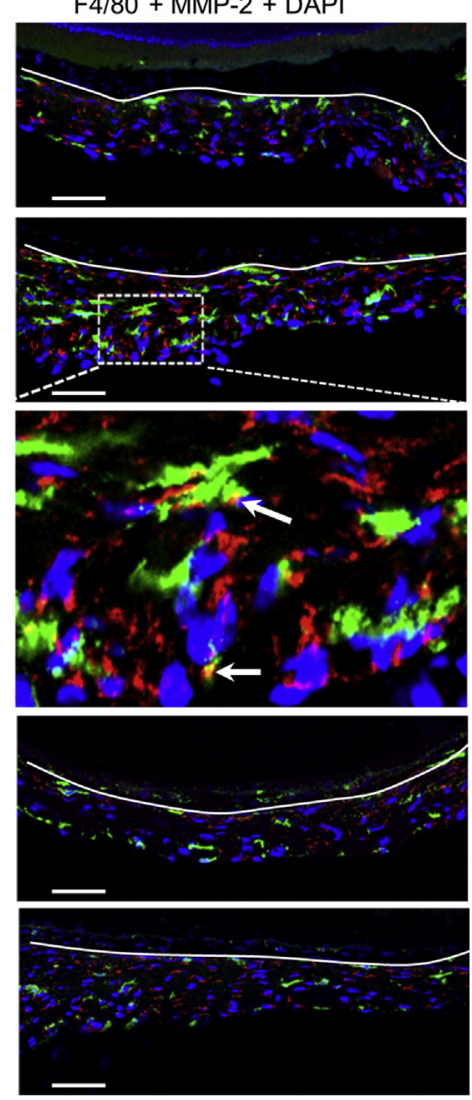

$\mathbf{F}$

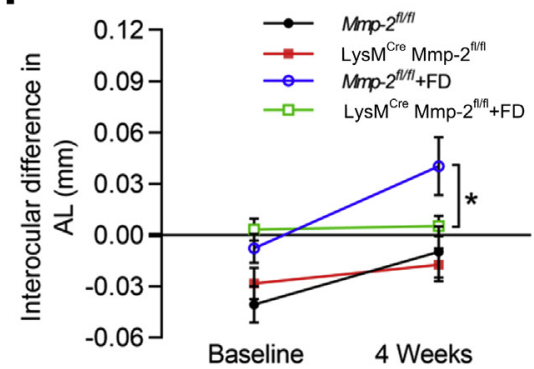

B<smiles>[131I-]</smiles>
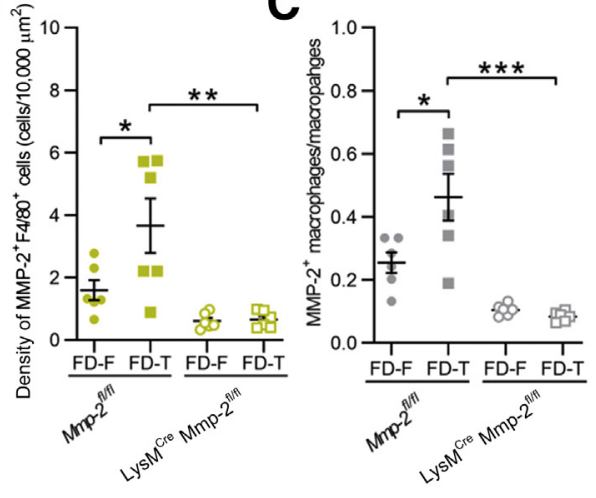

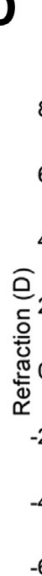

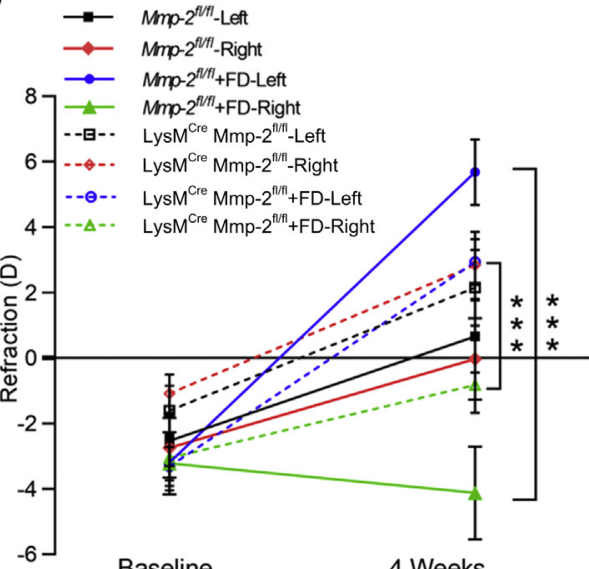

G

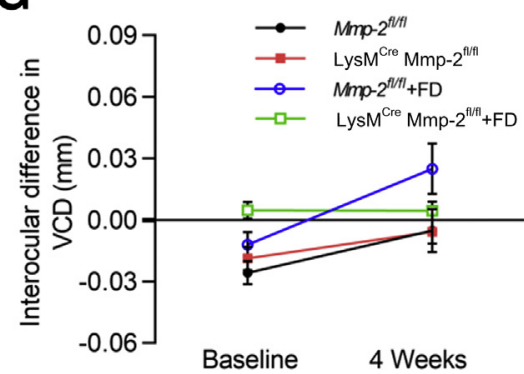

Figure 6 Suppression of form-deprivation(FD)-induced scleral macrophage matrix metallopeptidase 2 (MMP-2) up-regulation and myopia development in Lys $M^{\mathrm{Cre}} \mathrm{Mmp}-2^{f / / f l}$ mice. A: Representative images depicting $\mathrm{F} 4 / 80^{+} \mathrm{MMP}-2^{+}$signals (left column; green + red) and MMP- $2^{+} \mathrm{F} 4 / 80^{+}$signals with DAPI nuclear staining (right column; green + red + blue) of scleral sections obtained from FD-treated (FD-T) and untreated fellow (FD-F) eyes in Mmp $2^{f l f l}$ and LysM ${ }^{\text {Cre }}$ Mmp$2^{\mathrm{fl} / \mathrm{fl}}$ mice after 4 weeks of FD. The middle row shows the detailed magnification of the sclera, and the arrows in the left column point to the same cells shown in the right column. White solid lines indicate scleral margin to the choroid. B and C: Densities of MMP- $2^{+} \mathrm{F} 4 / 80^{+}$cells and the ratio of all $\mathrm{F} 4 / 80^{+}$cells that are MMP- $2^{+}$in scleras. D: Refraction: Four weeks of FD induces significant myopia in both Mmp $2^{f l f l}\left(M m p 2^{f l / f l}+\mathrm{FD}\right)$ and Lys $\mathrm{M}^{\mathrm{Cre}} \mathrm{Mmp}-2^{\mathrm{fl} / \mathrm{fl}} \mathrm{mice}\left(\mathrm{Lys} \mathrm{M}^{\mathrm{Cre}} \mathrm{Mmp}-\right.$ $\left.2^{\mathrm{fl} / \mathrm{fl}}+\mathrm{FD}\right) . \mathrm{Mmp2} 2^{\mathrm{fl} / \mathrm{fl}}$ and LysM $\mathrm{M}^{\mathrm{Cre}} \mathrm{Mmp}-2^{\mathrm{fl} / f l}$ mice without FD are shown for comparison. Right side: $\mathrm{FD}-\mathrm{T}$ eyes of FD-treated mice or right eyes of untreated mice. Left side: FD-F eyes of FD-treated mice or left eyes of untreated mice. E-G: Interocular differences (values for FD-T eyes minus those for FD-F eyes in the FD mice, or values for right eyes minus those for left eyes in mice without FD treatment) in refraction (E), axial length ( $A L$; $F$ ), and vitreous chamber depth $(\mathrm{VCD} ; \mathbf{G})$ of $M m p 2^{f l f f l}, \mathrm{LysM}^{\mathrm{Cre}} \mathrm{Mmp}-2^{\mathrm{fl} / \mathrm{fl}}, M m p 2^{f l f l}+\mathrm{FD}$, and Lys $\mathrm{M}^{\mathrm{Cre}} \mathrm{Mmp}-2^{f l f l}+\mathrm{FD}$ groups. Baseline indicates before FD, and 4 weeks indicates 4 weeks after FD. Data in $\mathbf{B}$ and $\mathbf{C}$ were analyzed using a two-way analysis of variance with Bonferroni post hoc tests, and data in $\mathbf{D}-\mathbf{G}$ were analyzed using a two-way repeated-measure analysis of variance with Bonferroni post hoc tests. Each data point represents an independent mouse (B and $\mathbf{C})$. Data are expressed as means \pm SEM $(\mathbf{B}-\mathbf{G}) . n=6$ mice for each group $(\mathbf{B}$ and $\mathbf{C}) ; n=10 \mathrm{Mmp} 2^{f l / f l}$ mice and Lys $\mathrm{M}^{\mathrm{Cre}} \mathrm{Mmp}-2^{\mathrm{fl} / \mathrm{fl}}$ mice $(\mathbf{D}-\mathbf{G}) ; n=14 \mathrm{Mmp} 2^{f l / f l}+\mathrm{FD}$ mice $(\mathbf{D}-\mathbf{G})$ and $n=24 \mathrm{LysM}^{\mathrm{Cre}} \mathrm{Mmp}-2^{\mathrm{fl} / \mathrm{fl}}+\mathrm{FD}$ mice $(\mathbf{D}-\mathbf{G}) .{ }^{*} P<0.05,{ }^{* *} P<0.01$, and ${ }^{* *} P<0.001$. Scale bars $=50 \mu \mathrm{m}(\mathbf{A})$. D, diopter.

less than that in $C c l 2^{f l / f}$ mice (main effect of genotype: $F_{1,43}=2.640, P=0.112 ; S 100 a 4^{C r e} C_{c l} 2^{f l f l}$ versus $C c 2^{f l f f}$ : $-0.9508 \pm 0.7332$ versus $-3.211 \pm 0.8073 \mathrm{D}, P=0.001$ ) (Figure 9D). AL and VCD were not significantly different between $S 100 a 4^{C r e} C_{C l} 2^{f / f l}$ and $C c l 2^{f / f l}$ mice (AL:
$F_{1,43}=0.002, P=0.966 ; S 100 a 4^{C r e} C c l 2^{f l / f l}$ versus $C c 2^{f f f f}$ : $-0.0106 \pm 0.0128$ versus $-0.0007 \pm 0.0113 \mathrm{~mm}$, $P=0.634 ; \quad$ VCD: $F_{1,43}=0.211, \quad P=0.649$ $S 100 a 4^{C r e} C c l 2^{f / f l}$ versus $C c l 2^{f l f l}:-0.0109 \pm 0.0114$ versus $-0.0009 \pm 0.0084 \mathrm{~mm}, P=0.211$ ) (Figure 9, $\mathrm{E}$ and F). 

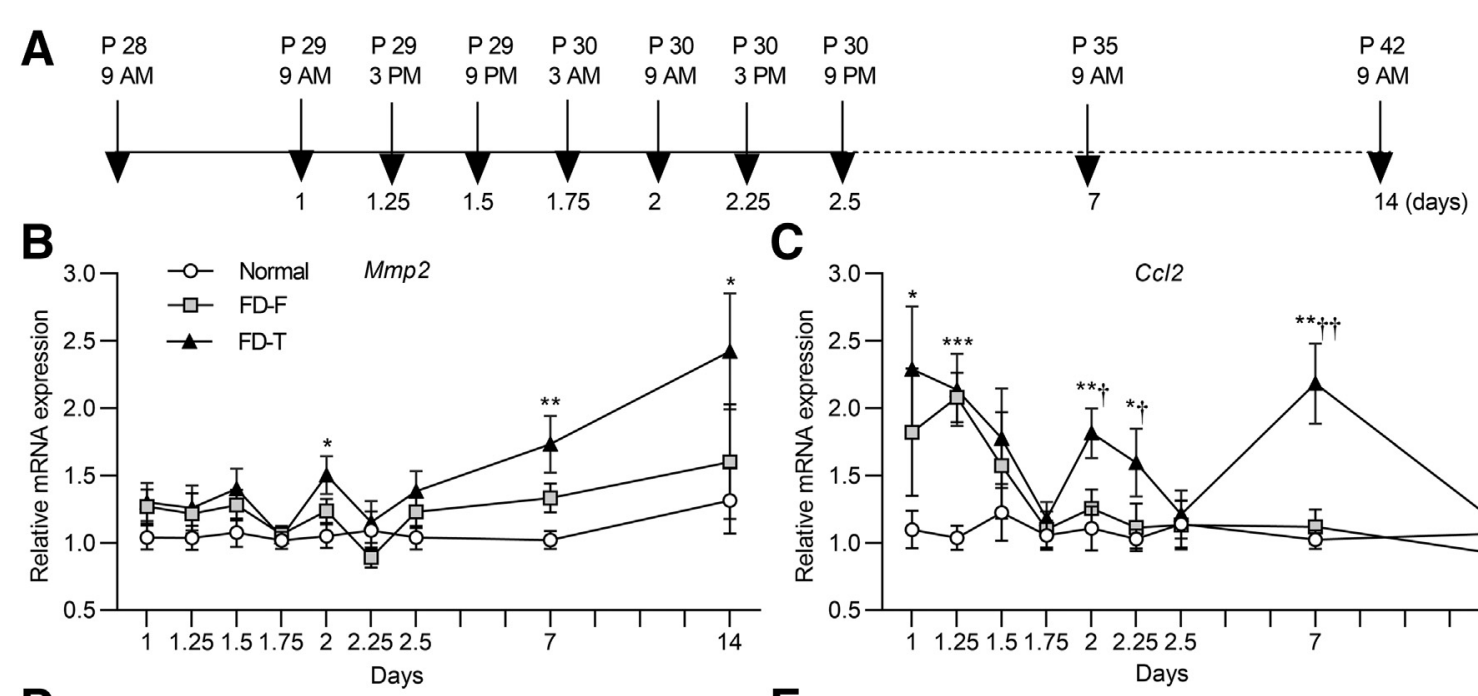

C
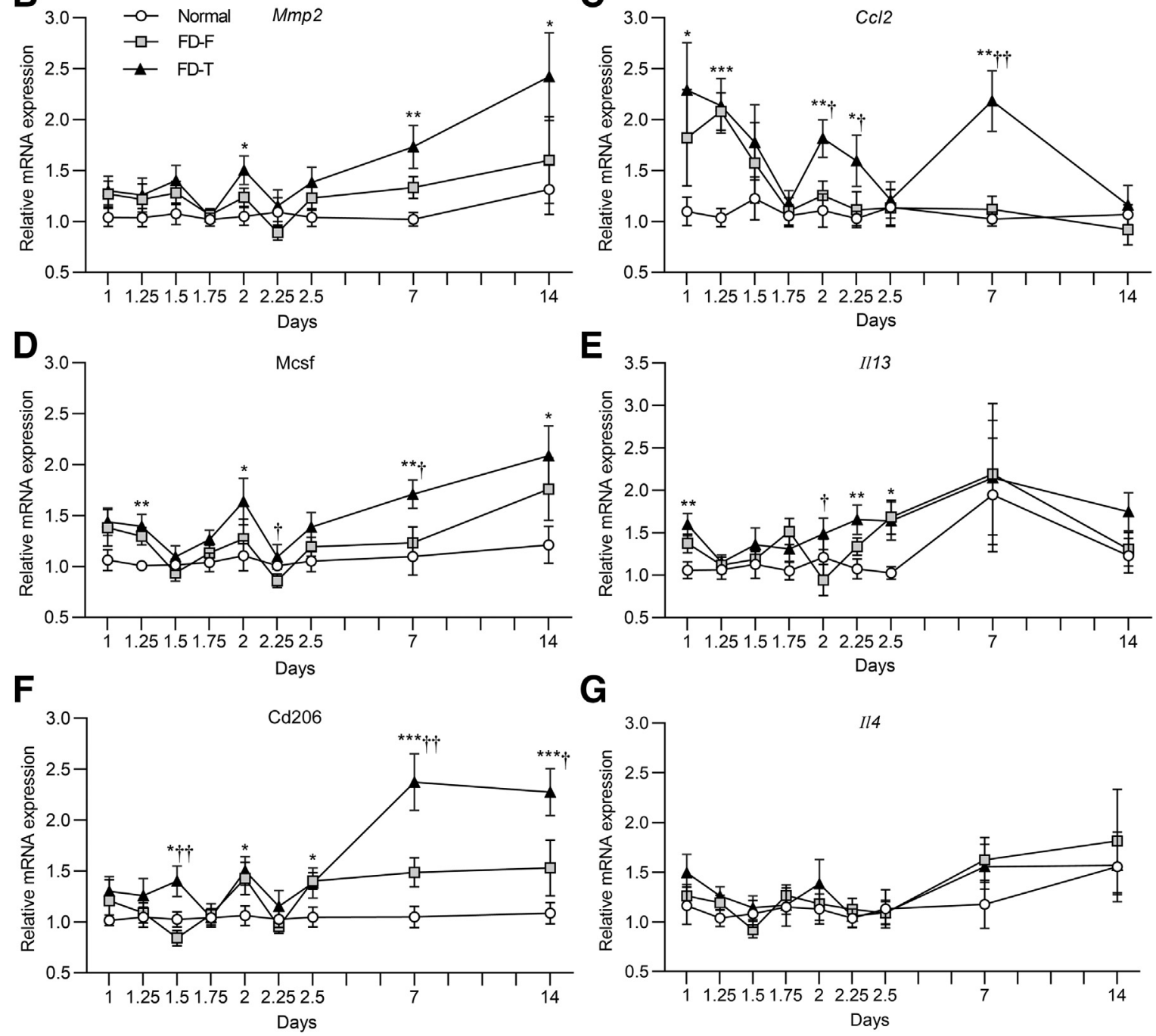

Figure 7 Time-dependent changes in mRNA expression levels of scleral macrophage-related genes. A: Schematic of experimental design of quantitative real-time RT-PCR (RT-qPCR) analysis. B-G: Quantification of mRNA expression levels of Mmp-2 (Mmp2) (B), Ccl2 (C), Mcsf (Csf1) (D), Il-13 (Il13) (E), Cd206 $($ Mrc1) (F), and Il-4 (Il4) (G) in sclera during form-deprivation (FD) myopia (FDM) progression. 18s rRNA was used as the reference gene. Data in B-G were analyzed using one-way analysis of variance with Bonferroni post hoc tests (for normally distributed data) and Kruskal-Wallis nonparametric test with Dunn post hoc test (for nonnormally distributed data). Data are expressed as means \pm SEM (B-G). For the different time points $(1,1.25,1.5,1.75,2,2.25,2.5,7$, and 14 days), $n=12,11,12,10,13,12,11,10$, and 16 normal mice; $n=12,11,11,11,13,11,11,12$, and 14 FD-induced mice. ${ }^{*} P<0.05$, ${ }^{* *} P<0.01$, and ${ }^{* *} P<0.001 \mathrm{FD}$-treated (FD-T) versus normal; ${ }^{\dagger} P<0.05,{ }^{\dagger \dagger} P<0.01 \mathrm{FD}-\mathrm{T}$ versus untreated fellow eyes (FD-F). $\mathrm{P}$, postnatal day.

Taken together, these results indicate that declines in scleral $C c l 2$ expression by fibroblasts significantly suppressed the increase in scleral macrophage density and FDM development.

\section{Discussion}

In this study, we characterized the dynamic involvement of scleral monocyte-derived macrophages in myopia development by using a well-established FDM mouse model.
The results indicate that they contribute to this process through enhancing MMP-2 expression, which, in turn, promotes scleral ECM remodeling. This is a novel finding because fibroblasts previously were presumed to be the sole source of scleral MMP-2 up-regulation because they are the predominant cell type in the sclera. The current study was undertaken on the basis of many reports suggesting that macrophages also have a supportive role in ECM remodeling because macrophage-specific biomarker expression patterns were identified in the normal 

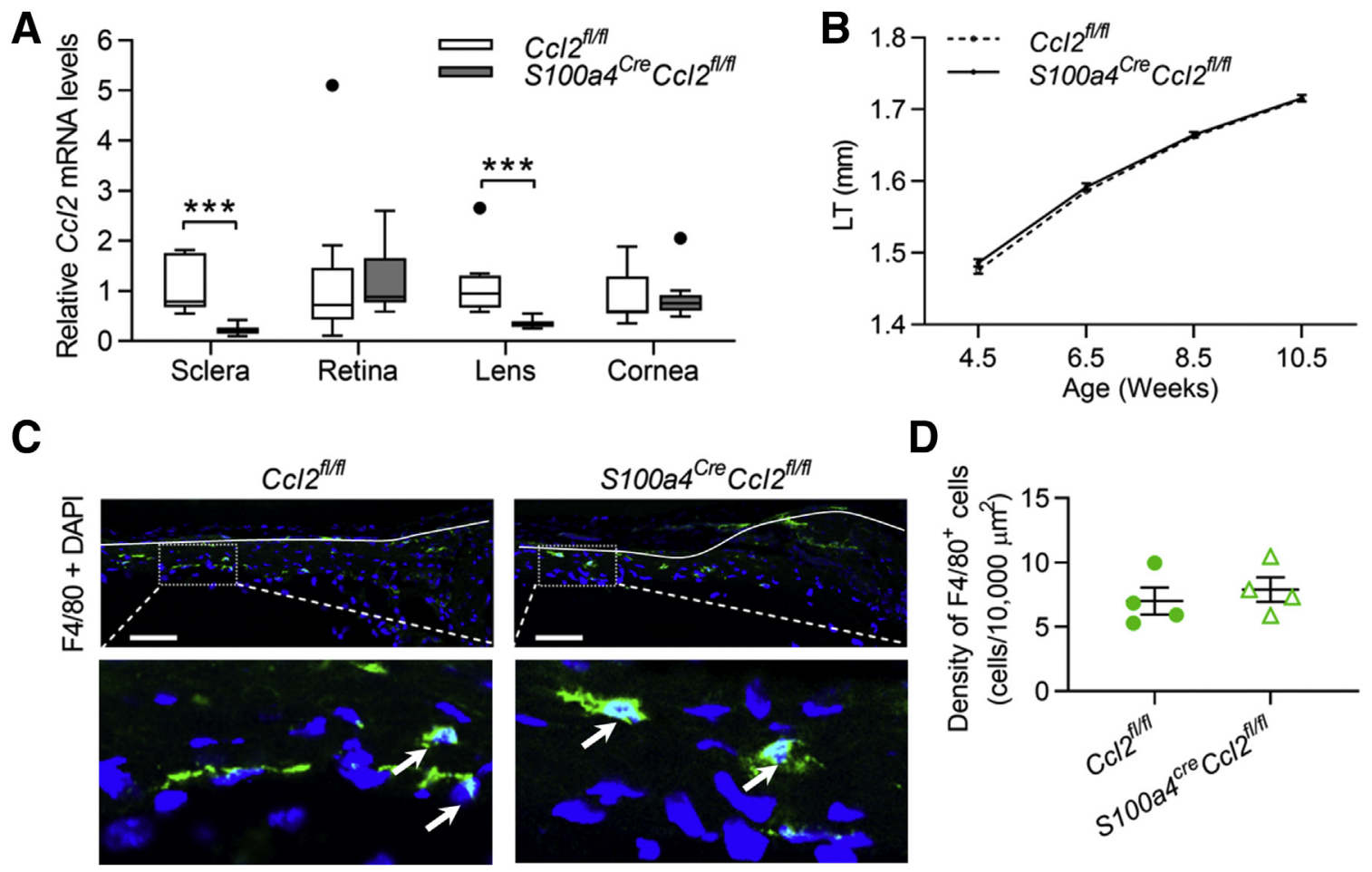

D
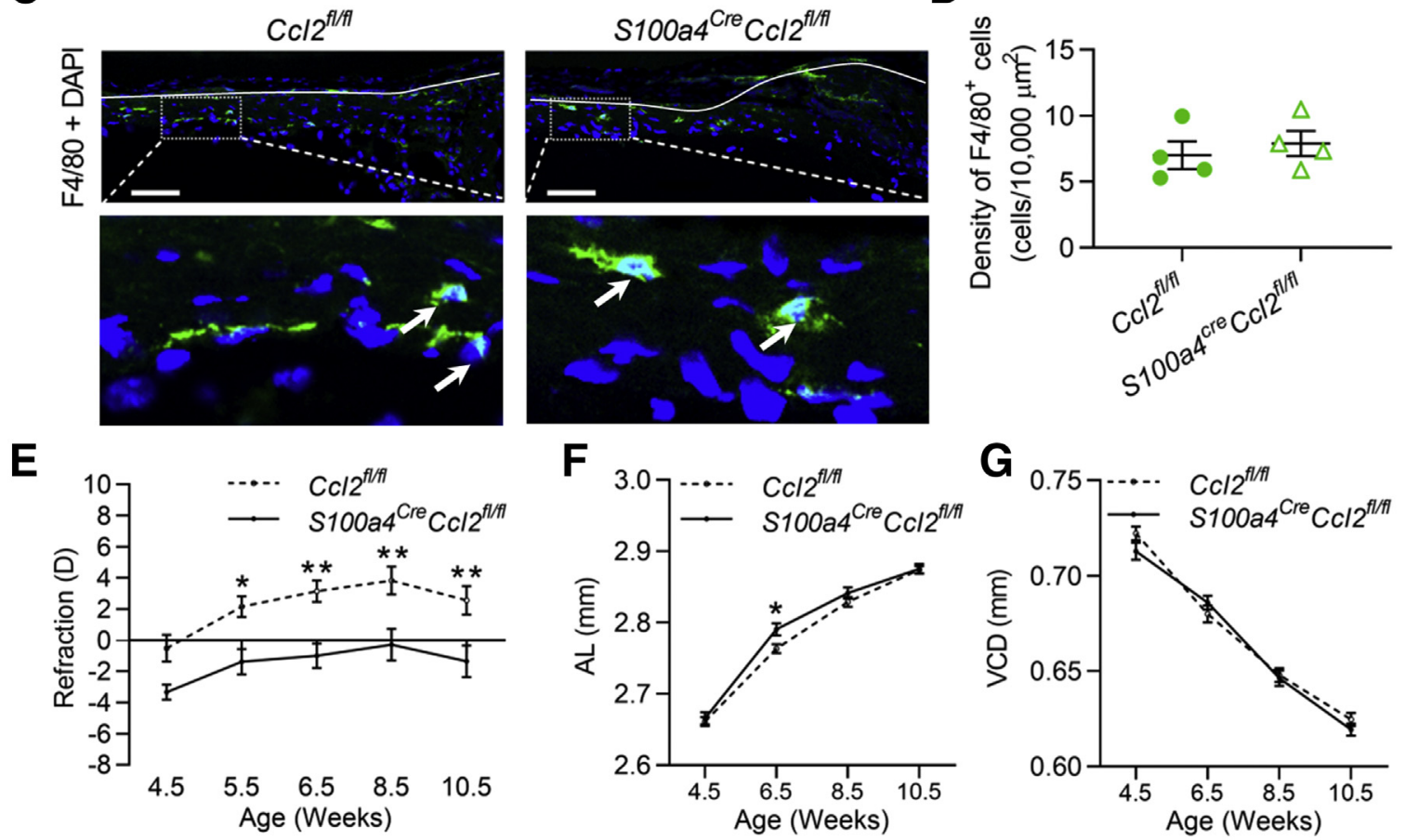

Figure 8 Retardation of refractive development in fibroblast-specific $C c l 2$ deletion ( $100 a 4^{\text {Cre }} \mathrm{Ccl} 2^{f l f l}$ ) mice. A: Quantitative real-time RT-PCR (RT-qPCR) analysis of $C c l 2$ mRNA expression levels in $C c l 2^{f l f l}$ and $S 100 a 4^{C r e} C c l 2^{f l f l}$ mice. $C c l 2$ expression levels were normalized to those of $C c l 2^{f l f l}$, and $18 \mathrm{~s}$ rRNA was used as the reference gene. B: Lens thickness (LT) of the Ccl2 fl/fl and S100a4 ${ }^{C r e} C c l 2^{f l f l}$ mice. C: Representative images depicting F4/80-immunostained macrophages with DAPI nuclear staining (top row; green + blue) of scleral sections obtained from $\mathrm{Ccl} 2^{f l f f l}$ and $S 100 a 4^{\mathrm{Cre}} \mathrm{Ccl}{ }^{f l f l}$ mice. The bottom row shows the detailed magnification of the sclera, and the arrows point to $\mathrm{F} 4 / 80^{+}$macrophages. White solid lines indicate scleral margin to the choroid. D: Density of $\mathrm{F} 4 / 80^{+}$cells. Each data point represents an independent mouse. $\mathbf{E}-\mathbf{G}$ : Refraction (E), axial length (AL; F), and vitreous chamber depth (VCD; G) of the $\mathrm{Ccl} 2^{f l f l}$ and $S 100 a 4^{C r e} C \mathrm{Cl} 2^{f l f f l}$ mice at the indicated ages during normal refractive development. Data in $\mathbf{A}$ and $\mathbf{D}$ were analyzed using unpaired two-tailed $t$ tests or $\mathbf{U}$-tests (for nonparametric data), and data in $\mathbf{B}$ and $\mathbf{E}-\mathbf{G}$ were analyzed using a two-way repeated-measure analysis of variance with Bonferroni post hoc tests. Box-plot diagrams showing the distribution of the data; lines within the boxes indicate medians; bars, range; black dots, outliers (A). Data are expressed as means \pm SEM $(\mathbf{B}, \mathbf{D}$, and $\mathbf{E}-\mathbf{G}) . n=11 \mathrm{Ccl} 2^{f l f l}$ mice for sclera and retina and $S 100 a 4^{C r e} C c l 2^{f l f l}$ mice for retina $(\mathbf{A}) ; n=10 \mathrm{Ccl} 2^{f l / f l}$ mice for lens

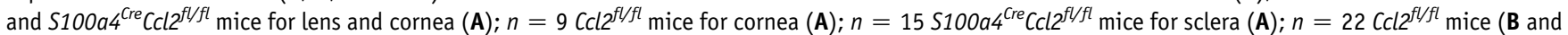
$\mathbf{E}-\mathbf{G}) ; n=265100 a 4^{\mathrm{Cre}} \mathrm{Ccl} \mathrm{f}^{f / f l}$ mice (B and $\left.\mathbf{E}-\mathbf{G}\right) ; n=4 \mathrm{Ccl} 2^{f l f l}$ mice and S100a4 $4^{\mathrm{Cre}} \mathrm{Ccl} 2^{f l / f l}$ mice (D). ${ }^{*} P<0.05,{ }^{* *} P<0.01$, and ${ }^{* * *} P<0.001$. Scale bars $=$ $50 \mu \mathrm{m}(\mathbf{C})$. D, diopter.

mammalian sclera. ${ }^{12-14}$ Another result indicating that scleral macrophages contribute to myopia development is that they develop dilated endoplasmic reticula during negative lens-induced myopia development in a nonclassic rabbit model. ${ }^{40}$ In addition, it was shown that parallel increases were identified in scleral macrophagelike cells that engulfed fibroblasts. However, it was not known if macrophages affect scleral ECM remodeling during myopia progression.
It was found that increases in scleral macrophage density accompanied myopia development in both the wild-type and LysM $^{\mathrm{Cr}}$ Rosa26 ${ }^{\mathrm{f} / \mathrm{fl}}$ mice. As shown in Figure 2, C and D, and Figure 3, B-D, scleral macrophage density in the FD-T eyes was not always higher than that in the age-matched normal eyes. Therefore, determining that a relationship exists between myopia development and increases in scleral macrophage density was solely based on comparing the changes in the contralateral untreated eye (FD-F) with those in the 
A

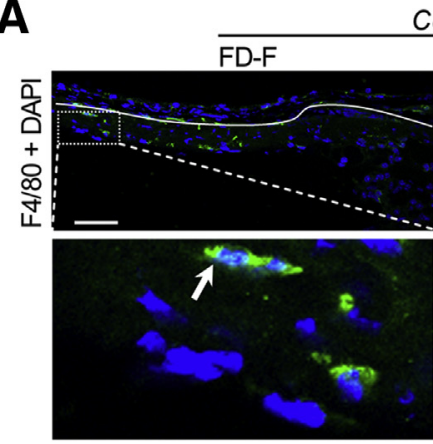

B

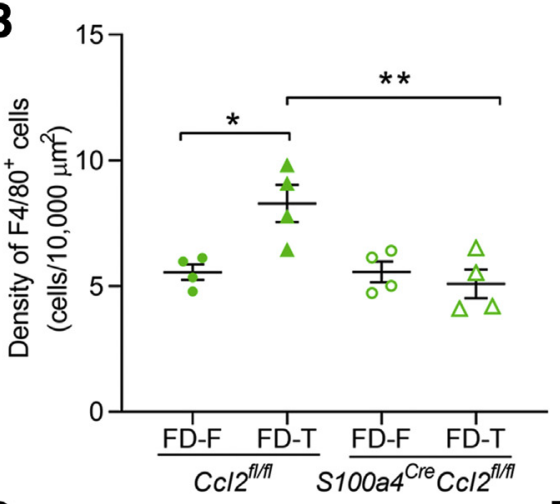

$\frac{C c / 2^{f / f f l}}{\text { FD-T }}$

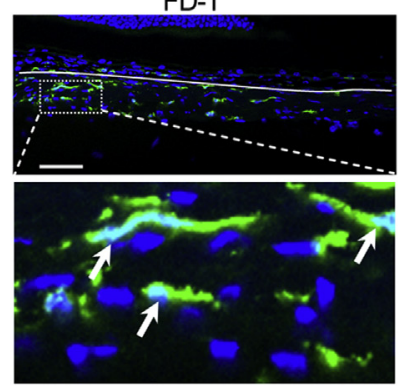

C
D

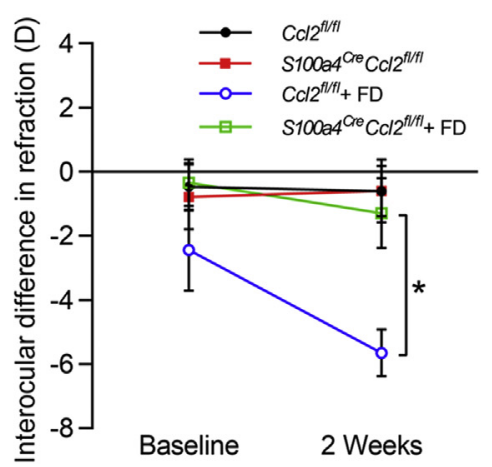

E

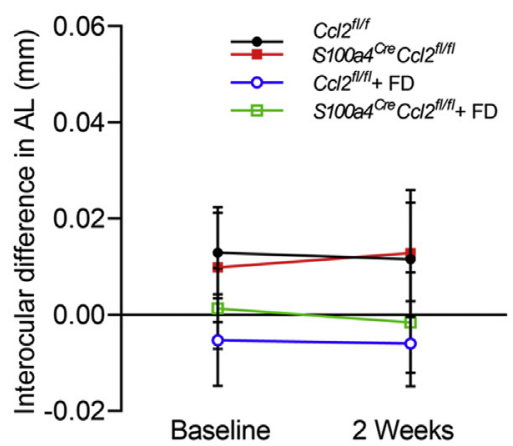

$S 100 \mathrm{a} 4^{\mathrm{Cre}} \mathrm{Cc} / 2^{\mathrm{fl} / \mathrm{fl}}$
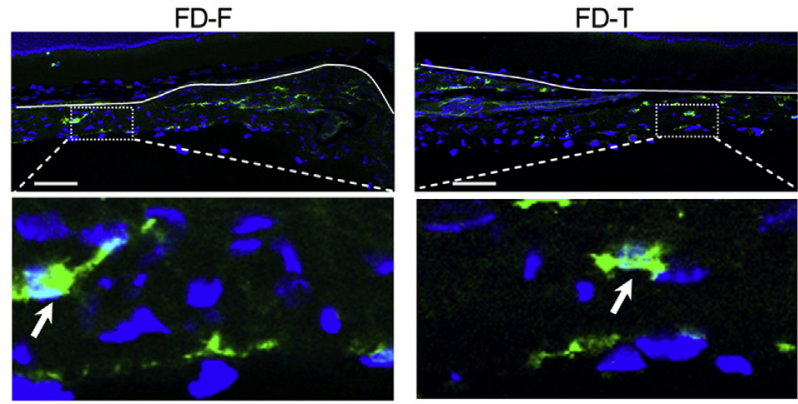

$\rightarrow \quad C c / 2^{f / t / t}-$ Left

$\because \quad \mathrm{Ccl} 2^{f / / t I}-$ Right

$\rightarrow \quad \mathrm{Ccl} 2^{f / f t}+\mathrm{FD}$-Left

- $\mathrm{Ccl} 2^{f|l| f \mid}+\mathrm{FD}-\mathrm{Right}$

$\rightarrow \quad S 100 a 4^{C r e} \mathrm{Cc} / 2^{f / f t}-$ Left

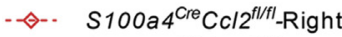

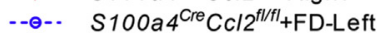

- $-A^{-} \cdot S 100 a 4^{\mathrm{Cre}} \mathrm{Cc} / 2^{f / f f}+\mathrm{FD}-$ Right

Figure 9 Attenuated form-deprivation (FD) myopia (FDM) development in scleral Ccl2 knockdown mice (S100a4 ${ }^{\mathrm{Cre}} \mathrm{Ccl} 2^{\mathrm{fl} / f l}$ ). A: Representative images showing F4/80 immunolabeled macrophages with DAPI nuclear staining (upper row; green + blue) of scleral sections obtained from $C c l 2^{f l f l}$ and $S 100 a 4^{\text {Cre }} \mathrm{Ccl} 2^{f / f l}$ mice after 2 weeks of $\mathrm{FD}$. The bottom row shows the detailed magnification of the sclera, and the arrows point to $\mathrm{F}^{\prime} / 80^{+}$macrophages. White solid lines indicate scleral margin to the choroid. B: Density of $\mathrm{F} 4 / 80^{+}$cells in the untreated fellow (FD-F) and FD-treated (FD-T) eyes of FD-treated $\mathrm{Ccl} 2^{f l f l}$ and $S 100 a 4^{C r e} \mathrm{Ccl} 2^{f l f l}$ mice. Each data point represents an independent mouse. C: Refraction: Two weeks of FD induces significant myopia in $\mathrm{Ccl} 2^{f / f l}$ mice

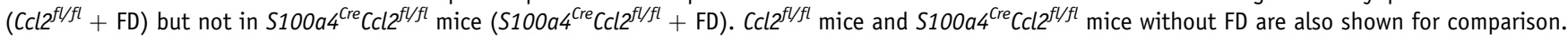
Right side: FD-T eyes of FD-treated mice or right eyes of untreated mice. Left side: FD-F eyes of FD-treated mice or left eyes of untreated mice. D-F: Interocular differences (values for FD-T eyes minus those for FD-F eyes in the FD mice, or values for right eyes minus those for left eyes in mice without FD treatment) in refraction (D), axial length (AL; E), and vitreous chamber depth (VCD; F). Data in $\mathbf{B}$ were analyzed using a two-way analysis of variance with Bonferroni post hoc tests, and data in $\mathbf{C}-\mathbf{F}$ were analyzed using a two-way repeated-measure analysis of variance with Bonferroni post hoc tests. Baseline indicates before $\mathrm{FD}$, and 2 weeks indicates 2 weeks after FD. Each data point represents an independent mouse (B). Data are expressed as means \pm SEM $(\mathbf{B}-\mathbf{F}) . n=4$ mice for each

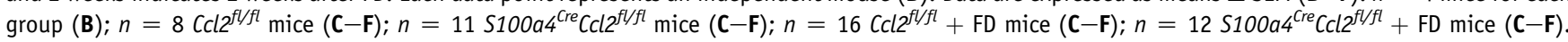
${ }^{*} P<0.05,{ }^{* *} P<0.01$, and ${ }^{* *} P<0.001$. Scale bars $=50 \mu \mathrm{m}(\mathbf{A})$. D, diopter.

deprived eye (FD-T). A yoking effect between the FD-F and FD-T eyes might be responsible for the lack of significant differences between the FD-T and normal eyes. Such an effect would blunt the differences between the FD-F and FD-T eyes and thereby mask the actual functional contribution of macrophages to myopia development during FD.

Besides, in the latter mice (LysM ${ }^{\mathrm{Cre}}$ Rosa26 ${ }^{\mathrm{f} / \mathrm{fl}}$ mice), colabeling of $\mathrm{F} 4 / 80^{+}$macrophages and the red tdTomato fluorescence expression was not consistent. This disconnect may be due to the presence of a heterogeneous population of F4/80 $0^{+}$and tdTomato ${ }^{+}$cells. Such variability is possible because the macrophage population may be composed of either different macrophage subtypes or macrophages in different maturational stages. F4/80 is a well-established mouse macrophage marker. ${ }^{26}$ The red tdTomato fluorescence expression is driven by the promoter of the $L y s M$ gene, 


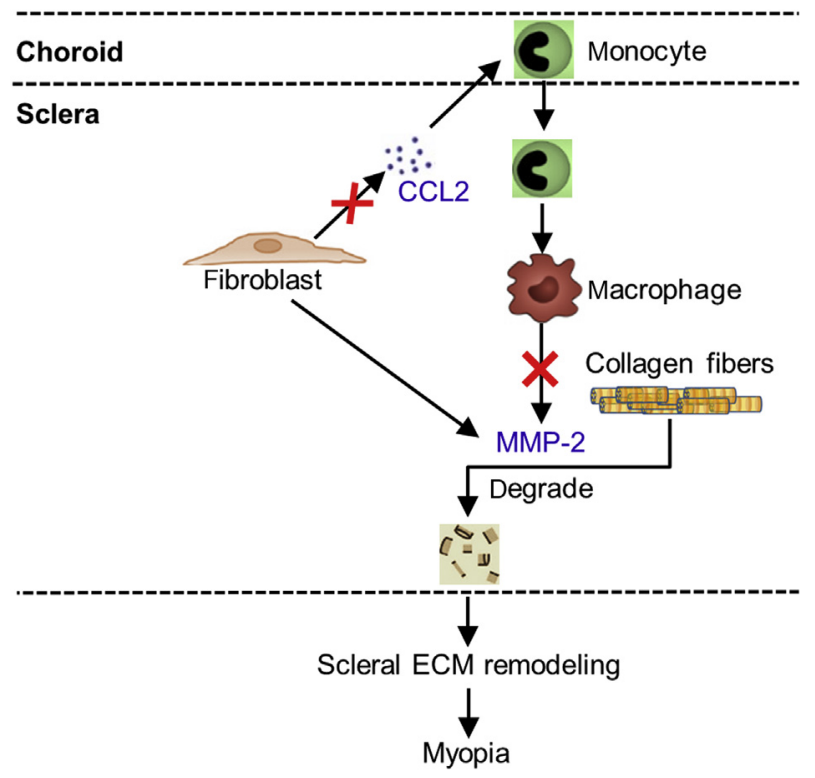

Figure 10 A schematic model describing scleral macrophage involvement in mediating form-deprivation (FD) myopia (FDM) development. FD induces up-regulation of scleral $\mathrm{C}-\mathrm{C}$ motif chemokine ligand-2 ( $\mathrm{Cl} / 2)$, which, in turn, recruits blood monocyte infiltration into the sclera. Subsequently, the monocytes undergo differentiation into matrix metallopeptidase 2 (MMP-2)-secreting macrophages, which augment type I collagen degradation and extracellular matrix (ECM) remodeling in myopia progression. Two red Xs mark possible sites to intervene in FDM through either fibroblast-specific $\mathrm{Ccl} 2$ deletion (upper red $\mathbf{X}$ ) or macrophagespecific Mmp2 deletion (lower red $\mathbf{X}$ ).

whose expression is limited to myeloid cells, including monocytes, mature macrophages, and granulocytes. ${ }^{20}$ It is not known if variability of tdTomato fluorescent marker expression could reflect a nonuniform expression pattern of different macrophage phenotypes in the sclera.

Importantly, the white signals in Figure 3A are a composite of red/green/blue, in the $\mathrm{LysM}^{\mathrm{Cre}} \mathrm{Rosa} 26^{\mathrm{fl} / \mathrm{fl}}$, originating from the red (driven by the lys $M$ gene) and green (F4/ 80 staining) immunoreactivity and the blue delimited DAPI nuclear staining. The subcellular localization of F4/80 protein (green signal in images) is mainly in the plasma membrane and extracellular, and its expression was also reported in nucleus, cytoskeleton, and cytosol (COMPARTMENTS subcellular localization database, https:// compartments.jensenlab.org, last accessed March 20, 2020). The tdTomato expression (red signal in images) in the macrophages is driven by the promoter of the lysozyme 2 gene, whose expression was located in an extracellular region, lysosome, plasma membrane, cytoskeleton, and nucleus (COMPARTMENTS subcellular localization database). One explanation for this blue/green/ red colabeling signal is that the nuclei of the macrophage are too large to overlap the green/red signals. In addition, the scleral frozen sections subjected to analysis with confocal microscopy immunofluorescence are $12 \mu \mathrm{m}$ thick, and these three different color signals may be captured from multiple layers by this procedure.
Scleral macrophage content is modulated by changes in infiltration of circulating blood monocytes and resident macrophage proliferation. As a matter of fact, several results show that circulating monocytes are a major source. First, the scleral gene-expression profile in the FD-T eyes corresponded with that of the infiltrating monocyte-derived macrophages rather than the tissue resident macrophagederived macrophages (Figure 7, B-G). Furthermore, scleral Mmp2 mRNA up-regulation was preceded by significant increases in the expression of Cd206 (Mrcl) (a specific marker of monocyte-derived macrophages) as well as $\mathrm{Ccl}$, Mcsf (Csf1), and Il-13 (Ill3) genes, which promote circulating monocyte infiltration. These results substantiate the notion that Mmp2 up-regulation is likely to be also dependent on increases in the number of scleral macrophages derived from circulating monocytes.

Second, the density of scleral macrophages in the FD-T and FD-F eyes of CLOD-injected mice was significantly lower than in their respective counterparts (FD-T and FD-F eyes) of the LIP-injected mice (Figure 4, A and B). Nevertheless, an FD-induced increase in scleral macrophage density did not occur in the LIP-injected mice. One explanation for this negative effect of FD is that the ratio of $\mathrm{CD} 45^{+} \mathrm{CD} 11 \mathrm{~b}^{+} \mathrm{CD} 115^{+}$monocytes was significantly higher in the peripheral blood of LIP-injected mice than in noninjected normal mice (Supplemental Figure S9, A and B), which caused a similar increase in scleral macrophage density in both the FD-T and FD-F eyes of the LIP groups compared with their respective counterparts (FD-T and FD-F eyes) of the noninjected normal mice. This higher ratio of blood monocytes in the LIP-injected mice might be a response to possible cytotoxicity of the LIP vehicle. On the other hand, CLOD treatment failed to reduce FDM progression. This invariance might be due to similar reductions in scleral macrophage density in both the FD-T and FD-F eyes of the CLOD and the LIP groups. Another possibility is that CLOD injections did not completely deplete all the scleral macrophages. This lower efficacy of macrophage depletion in sclera than in liver might be due to the absence of scleral blood capillaries, ${ }^{25}$ which could delay drug buildup in the sclera relative to that in vascularized tissues. Nevertheless, it is still possible that increases in scleral resident macrophage proliferation occurred in parallel with monocyte recruitment during FDM development. In any case, further study is warranted using a more effective strategy to achieve sufficient scleral macrophage depletion to validate their involvement in myopia development. In addition, any potential adverse effect resulting from repeated injections of CLOD in mice were not accounted for. As shown by the developer of this drug ${ }^{36,41}$ the common adverse effects of CLOD injection are mainly related to the elimination of monocytes/macrophages. CLOD-mediated depletion of macrophages may have adverse effects on humoral immunity responses in other studies; however, CLOD did not produce any adverse effects, such as loss of motor control or activity levels, in the treated animals. ${ }^{42}$ 
The third line of evidence supporting that circulating monocytes are one of the major resources of increases in scleral macrophage density is that fibroblast-specific $\mathrm{Ccl} 2$ deletion suppressed this increase in scleral macrophage density along with inhibiting myopia development. This finding strongly implicates that fibroblast elaboration of CCL2 acts as a chemoattractant to draw circulating monocytes into the sclera and, in turn, promotes the response to the FD stimulus. Increases in CCL2 expression draw blood monocytes into the sclera, which are mainly originated from the capillaries of the adjacent choroidal tissue. Such a scenario is indicated because the choroid is a highly vascularized layer sandwiched between the sclera and the retina, whereas the sclera is avascular. ${ }^{43}$ There are several studies suggesting that monocyte infiltration into the sclera is modulated by changes in choroidal perfusion. These studies documented a significant decline in choroidal thickness ${ }^{44-46}$ or choroidal blood flow ${ }^{47,48}$ in human high myopic eyes. Similarly, a decline in choroidal blood flow was also observed in a chick myopia model ${ }^{49} \mathrm{~A}$ recent study provided evidence for corresponding significant declines in choroidal thickness and blood perfusion in guinea pig myopia models. ${ }^{50}$ Accordingly, obstructing blood flow may, in turn, compromise endothelial cell contact integrity and contribute to increases in choroidal vascular paracellular permeability. ${ }^{51}$ Such increase in junctional leakiness may facilitate scleral monocyte permeation from the choroid into the sclera. If this prediction is correct, it is conceivable that monocyte migration from the choroid into the sclera increases during FD, and thereby accentuates or sustains myopia development.

Macrophage activation can induce either antifibrotic or profibrotic responses during ECM remodeling. Two different pathways are involved in their antifibrotic role. One of them modulates ECM turnover through an extracellular pathway, which promotes ECM degradation via enhanced expression of MMPs. ${ }^{18,19,52,53}$ The other pathway achieves the same result through macrophage endocytosis, followed by lysosomal degradation. ${ }^{54,55}$ Because F4/80 and MMP-2 colabeling increased during myopia development, it is possible that the colabeling yellow signal may be indicative of macrophage phagocytosis of other cell types expressing MMP-2. Nevertheless, it is apparent that at least part of the increase was attributable to the increased scleral macrophage content because myopia development was significantly suppressed by loss of MMP-2 function in scleral macrophages.

Conditional deletion of Mmp2 in macrophages had no effect on scleral Mmp2 mRNA expression, suggesting that fibroblasts rather than macrophages are the major source of scleral MMP-2 in a normal visual environment. On the other hand, scleral macrophage MMP-2 deletion reduced myopia development by 59\%, whereas fibroblast-specific Mmp2 deletion decreased it by only $27 \%{ }^{6}$ This disconnect between the relatively low abundance of scleral macrophages but their appreciable contribution to FDM progression suggests that scleral macrophage MMP-2 up-regulation likely makes a significant contribution to scleral ECM remodeling. Nevertheless, further studies are warranted to delineate a possible role for the endocytosis pathway in mediating ECM remodeling by scleral macrophages during myopia development.

Certain subtypes of macrophages can induce profibrotic responses by directly promoting fibroblast-myofibroblast transdifferentiation and collagen deposition. Transforming growth factor (TGF) $\beta$ isoforms are members of one of the profibrotic cytokine families that mediate ECM remodeling through up-regulation. ${ }^{56}$ Specifically, TGF- $\beta$ (TGF- $\beta-1$, TGF- $\beta-2$, and TGF- $\beta-3$ ) isoforms are differentially expressed in the sclera of different animal models of myopia, and they are thought to be involved in ECM remodeling during myopia development. ${ }^{57}$ Accordingly, further studies are required to clarify whether any of these factors are released by profibrotic macrophages during myopia development.

In summary, Figure 10 provides a schematic representation describing how scleral monocyte-derived macrophages promote myopia development through up-regulating MMP-2 expression. According to the model, up-regulating CCL2 expression in scleral fibroblasts induces increases in the infiltration of blood monocytes from the choroidal blood into the sclera. Subsequently, these monocytes transdifferentiate into MMP-2-secreting macrophages. In addition to macrophages, scleral fibroblasts are another cellular source of MMP-2 up-regulation during myopia development. MMP-2 up-regulation is involved in inducing type I collagen degradation and ECM remodeling and, in turn, scleral thinning, AL elongation, and myopia development. These results should prompt further studies to determine if they are translatable to humans. If this is confirmed, the results obtained in this FDM mouse model provide novel targets that may improve therapeutic management of myopia.

\section{Acknowledgments}

We thank Heping Xu (Queen's University Belfast) and William K. Stell (University of Calgary) for support in manuscript preparation; and Guangyun Mao (Wenzhou Medical University) and Jingwei Zheng (Wenzhou Medical University) for statistical help.

\section{Supplemental Data}

Supplemental material for this article can be found at http://doi.org/10.1016/j.ajpath.2020.06.002.

\section{References}

1. Holden BA, Fricke TR, Wilson DA, Jong M, Naidoo KS Sankaridurg P, Wong TY, Naduvilath TJ, Resnikoff S: Global prevalence of myopia and high myopia and temporal trends from 2000 through 2050. Ophthalmology 2016, 123:1036-1042

2. Dolgin E: The myopia boom. Nature 2015, 519:276-278 
3. Ikuno Y: Overview of the complications of high myopia. Retina 2017, 37:2347-2351

4. Leo SW; Scientific Bureau of World Society of Paediatric Ophthalmology and Strabismus (WSPOS): Current approaches to myopia control. Curr Opin Ophthalmol 2017, 28:267-275

5. Rada JA, Shelton S, Norton TT: The sclera and myopia. Exp Eye Res 2006, 82:185-200

6. Zhao F, Zhou Q, Reinach PS, Yang J, Ma L, Wang X, Wen Y, Srinivasalu N, Qu J, Zhou X: Cause and effect relationship between changes in scleral matrix metallopeptidase- 2 expression and myopia development in mice. Am J Pathol 2018, 188:1754-1767

7. Guggenheim JA, McBrien NA: Form-deprivation myopia induces activation of scleral matrix metalloproteinase-2 in tree shrew. Invest Ophthalmol Vis Sci 1996, 37:1380-1395

8. Jones BE, Thompson EW, Hodos W, Waldbillig RJ, Chader GJ: Scleral matrix metalloproteinases, serine proteinase activity and hydrational capacity are increased in myopia induced by retinal image degradation. Exp Eye Res 1996, 63:369-381

9. Rada JA, Perry CA, Slover ML, Achen VR: Gelatinase A and TIMP2 expression in the fibrous sclera of myopic and recovering chick eyes. Invest Ophthalmol Vis Sci 1999, 40:3091-3099

10. Siegwart JT, Norton TT: The time course of changes in mRNA levels in tree shrew sclera during induced myopia and recovery. Invest Ophthalmol Vis Sci 2002, 43:2067-2075

11. Qian L, Zhao H, Li X, Yin J, Tang W, Chen P, Wang Q, Zhang J: Pirenzepine inhibits myopia in guinea pig model by regulating the balance of MMP-2 and TIMP-2 expression and increased tyrosine hydroxylase levels. Cell Biochem Biophys 2015, 71:1373-1378

12. Schlereth SL, Kremers S, Schrödl F, Cursiefen C, Heindl LM: Characterization of antigen-presenting macrophages and dendritic cells in the healthy human sclera. Invest Ophthalmol Vis Sci 2016, $57: 4878-4885$

13. Schlereth SL, Neuser B, Caramoy A, Grajewski RS, Koch KR, Schrödl F, Cursiefen C, Heindl LM: Enrichment of lymphatic vessel endothelial hyaluronan receptor 1 (LYVE1)-positive macrophages around blood vessels in the normal human sclera. Invest Ophthalmol Vis Sci 2014, 55:865-872

14. Xu H, Chen M, Reid DM, Forrester JV: LYVE-1-positive macrophages are present in normal murine eyes. Invest Ophthalmol Vis Sci 2007, 48:2162-2171

15. Wynn TA, Barron L: Macrophages: master regulators of inflammation and fibrosis. Semin Liver Dis 2010, 30:245-257

16. Krzyszczyk P, Schloss R, Palmer A, Berthiaume F: The role of macrophages in acute and chronic wound healing and interventions to promote pro-wound healing phenotypes. Front Physiol 2018, 9:419

17. Mahdavian Delavary B, van der Veer WM, van Egmond $M$, Niessen FB, Beelen RH: Macrophages in skin injury and repair. Immunobiology 2011, 216:753-762

18. Aoki T, Kataoka H, Morimoto M, Nozaki K, Hashimoto N: Macrophage-derived matrix metalloproteinase-2 and -9 promote the progression of cerebral aneurysms in rats. Stroke 2007, 38:162-169

19. Oviedo-Orta E, Bermudez-Fajardo A, Karanam S, Benbow U, Newby AC: Comparison of MMP-2 and MMP-9 secretion from T helper 0,1 and 2 lymphocytes alone and in coculture with macrophages. Immunology 2008, 124:42-50

20. Clausen BE, Burkhardt C, Reith W, Renkawitz R, Forster I: Conditional gene targeting in macrophages and granulocytes using LysMcre mice. Transgenic Res 1999, 8:265-277

21. Madisen L, Zwingman TA, Sunkin SM, Oh SW, Zariwala HA, Gu H, Ng LL, Palmiter RD, Hawrylycz MJ, Jones AR, Lein ES, Zeng H: A robust and high-throughput Cre reporting and characterization system for the whole mouse brain. Nat Neurosci 2010, 13:133-140

22. Takahashi M, Galligan C, Tessarollo L, Yoshimura T: Monocyte chemoattractant protein-1 (MCP-1), not MCP-3, is the primary chemokine required for monocyte recruitment in mouse peritonitis induced with thioglycollate or zymosan A. J Immunol 2009, 183:3463-3471
23. Tsutsumi R, Xie C, Wei X, Zhang M, Zhang X, Flick LM, Schwarz EM, O'Keefe RJ: PGE2 signaling through the EP4 receptor on fibroblasts upregulates RANKL and stimulates osteolysis. J Bone Miner Res 2009, 24:1753-1762

24. Schaeffel F, Burkhardt E, Howland HC, Williams RW: Measurement of refractive state and deprivation myopia in two strains of mice. Optom Vis Sci 2004, 81:99-110

25. Zhou X, Shen M, Xie J, Wang J, Jiang L, Pan M, Qu J, Lu F: The development of the refractive status and ocular growth in C57BL/6 mice. Invest Ophthalmol Vis Sci 2008, 49:5208-5214

26. Austyn JM, Gordon S: F4/80, a monoclonal antibody directed specifically against the mouse macrophage. Eur J Immunol 1981, 11: $805-815$

27. Brinckerhoff CE, Matrisian LM: Matrix metalloproteinases: a tail of a frog that became a prince. Nat Rev Mol Cell Biol 2002, 3:207-214

28. van Rooijen N, van Kesteren-Hendrikx E: Clodronate liposomes: perspectives in research and therapeutics. J Liposome Res 2002, 12: $81-94$

29. Feng B, Jiao P, Nie Y, Kim T, Jun D, van Rooijen N, Yang Z, Xu H: Clodronate liposomes improve metabolic profile and reduce visceral adipose macrophage content in diet-induced obese mice. PLoS One 2011, 6:e24358

30. Moreno SG: Depleting macrophages in vivo with clodronate-liposomes. Methods Mol Biol 2018, 1784:259-262

31. Bu L, Gao M, Qu S, Liu D: Intraperitoneal injection of clodronate liposomes eliminates visceral adipose macrophages and blocks highfat diet-induced weight gain and development of insulin resistance. AAPS J 2013, 15:1001-1011

32. Sunderkotter C, Nikolic T, Dillon MJ, Van Rooijen N, Stehling M, Drevets DA, Leenen PJ: Subpopulations of mouse blood monocytes differ in maturation stage and inflammatory response. J Immunol 2004, 172:4410-4417

33. Zhou X, Ji F, An J, Zhao F, Shi F, Huang F, Li Y, Jiao S, Yan D, Chen X, Chen J, Qu J: Experimental murine myopia induces collagen type Ialpha1 (COL1A1) DNA methylation and altered COL1A1 messenger RNA expression in sclera. Mol Vis 2012, 18:1312-1324

34. Livak KJ, Schmittgen TD: Analysis of relative gene expression data using real-time quantitative PCR and the $2-\Delta \Delta C T$ method. Methods 2001, 25:402-408

35. Howlett MH, McFadden SA: Form-deprivation myopia in the guinea pig (Cavia porcellus). Vis Res 2006, 46:267-283

36. Rooijen NV, Sanders A: Liposome mediated depletion of macrophages: mechanism of action, preparation of liposomes and applications. J Immunol Methods 1994, 174:83-93

37. van Amerongen MJ, Harmsen MC, van Rooijen N, Petersen AH, van Luyn MJA: Macrophage depletion impairs wound healing and increases left ventricular remodeling after myocardial injury in mice. Am J Pathol 2007, 170:818-829

38. Murray PJ, Wynn TA: Protective and pathogenic functions of macrophage subsets. Nat Rev Immunol 2011, 11:723-737

39. Gundra UM, Girgis NM, Ruckerl D, Jenkins S, Ward LN, Kurtz ZD, Wiens KE, San Tang M, Basu-Roy U, Mansukhani A: Alternatively activated macrophages derived from monocytes and tissue macrophages are phenotypically and functionally distinct. Blood 2014, 123 : e110-e122

40. Lin X, Wang B-J, Wang Y-C, Chu R-Y, Dai J-H, Zhou X-T, Qu X-M, Liu H, Zhou H: Scleral ultrastructure and biomechanical changes in rabbits after negative lens application. Int J Ophthalmol 2018, 11:354-362

41. van Rooijen N, Sanders A, van den Berg TK: Apoptosis of macrophages induced by liposome-mediated intracellular delivery of clodronate and propamidine. J Immunol Methods 1996, 193:93-99

42. Bonabello A, Galmozzi MR, Canaparo R, Serpe L, Zara GP: Longterm analgesic effect of clodronate in rodents. Bone 2003, 33: 567-574

43. Watson PG, Young RD: Scleral structure, organisation and disease: a review. Exp Eye Res 2004, 78:609-623 
44. Harb E, Hyman L, Gwiazda J, Marsh-Tootle W, Zhang Q, Hou W, Norton TT, Weise K, Dirkes K, Zangwill LM; COMET Study Group: Choroidal thickness profiles in myopic eyes of young adults in the correction of myopia evaluation trial cohort. Am J Ophthalmol 2015, 160:62-71

45. Liu B, Wang Y, Li T, Lin Y, Ma W, Chen X, Lyu C, Li Y, Lu L: Correlation of subfoveal choroidal thickness with axial length, refractive error, and age in adult highly myopic eyes. BMC Ophthalmol 2018, 18:127

46. Fujiwara T, Imamura Y, Margolis R, Slakter JS, Spaide RF: Enhanced depth imaging optical coherence tomography of the choroid in highly myopic eyes. Am J Ophthalmol 2009, 148:445-450

47. Yang YS, Koh JW: Choroidal blood flow change in eyes with high myopia. Korean J Ophthalmol 2015, 29:309-314

48. Shih YF, Horng IH, Yang CH, Lin LL, Peng Y, Hung PT: Ocular pulse amplitude in myopia. J Ocul Pharmacol 1991, 7:83-87

49. Shih YF, Fitzgerald ME, Norton TT, Gamlin PD, Hodos W, Reiner A: Reduction in choroidal blood flow occurs in chicks wearing goggles that induce eye growth toward myopia. Curr Eye Res 1993, 12:219-227

50. Zhang S, Zhang G, Zhou X, Xu R, Wang S, Guan Z, Lu J, Srinivasalu N, Shen M, Jin Z, Qu J, Zhou X: Changes in choroidal thickness and choroidal blood perfusion in guinea pig myopia changes in choroidal blood perfusion in guinea pig myopia. Invest Ophthalmol Vis Sci 2019, 60:3074-3083
51. Nickla DL, Wallman J: The multifunctional choroid. Prog Retin Eye Res 2010, 29:144-168

52. Fallowfield JA, Mizuno M, Kendall TJ, Constandinou CM, Benyon RC, Duffield JS, Iredale JP: Scar-associated macrophages are a major source of hepatic matrix metalloproteinase-13 and facilitate the resolution of murine hepatic fibrosis. J Immunol 2007, 178: $5288-5295$

53. Wang W, Xu B, Xuan H, Ge Y, Wang Y, Wang L, Huang J, Fu W, Michie SA, Dalman RL: Hypoxia-inducible factor 1 in clinical and experimental aortic aneurysm disease. J Vasc Surg 2017, 68:1538-1550

54. Madsen DH, Bugge TH: Imaging collagen degradation in vivo highlights a key role for M2-polarized macrophages in extracellular matrix degradation. Oncoimmunology 2013, 2:e27127

55. Madsen DH, Leonard D, Masedunskas A, Moyer A, Jurgensen HJ, Peters DE, Amornphimoltham P, Selvarj A, Yamada SS, Brenner DA, Burgdorf S, Engelholm LH, Behrendt N, Holmbeck K, Weigert R, Bugge TH: M2-like macrophages are responsible for collagen degradation through a mannose receptor-mediated pathway. J Cell Biol 2013, 202:951-966

56. Biernacka A, Dobaczewski M, Frangogiannis NG: TGF- $\beta$ signaling in fibrosis. Growth Factors 2011, 29:196-202

57. Jobling AI, Nguyen M, Gentle A, McBrien NA: Isoform-specific changes in scleral transforming growth factor-beta expression and the regulation of collagen synthesis during myopia progression. J Biol Chem 2004, 279:18121-18126 